\title{
Development of the INL Thermal Energy Distribution System (TEDS) in the Modelica Ecosystem for Validation and Verification
}

\section{July 2020}

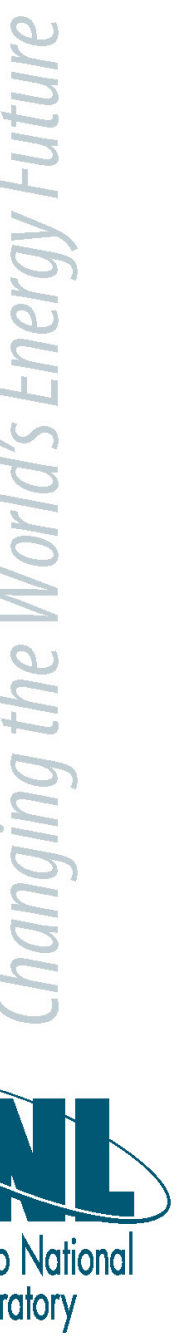

Konor Frick, Ph.D.

Shannon Bragg-Sitton, Ph.D.

Cristian Rabiti, Ph.D

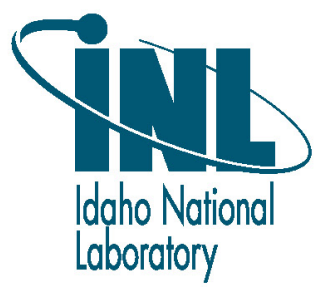




DISCLAIMER
This information was prepared as an account of work sponsored by an
agency of the U.S. Government. Neither the U.S. Government nor any
agency thereof, nor any of their employees, makes any warranty, expressed
or implied, or assumes any legal liability or responsibility for the accuracy,
completeness, or usefulness, of any information, apparatus, product, or
process disclosed, or represents that its use would not infringe privately
owned rights. References herein to any specific commercial product,
process, or service by trade name, trade mark, manufacturer, or otherwise,
does not necessarily constitute or imply its endorsement, recommendation,
or favoring by the U.S. Government or any agency thereof. The views and
opinions of authors expressed herein do not necessarily state or reflect
those of the U.S. Government or any agency thereof.




\section{Development of the INL Thermal Energy Distribution System (TEDS) in the Modelica Ecosystem for Validation and Verification}

Konor Frick, Ph.D.

Shannon Bragg-Sitton, Ph.D.

Cristian Rabiti, Ph.D

July 2020

Idaho National Laboratory

Idaho Falls, Idaho 83415

http://www.inl.gov

Prepared for the

U.S. Department of Energy

Office of Nuclear Energy

Under DOE Idaho Operations Office

Contract DE-AC07-05ID14517 
Page intentionally left blank 


\section{ABSTRACT}

This report provides an overview on the development of the Thermal Energy Distribution System (TEDS) in the Modelica process model ecosystem at Idaho National Laboratory (INL) as part of the Integrated Energy Systems program.

Model development has led to the creation of a dynamic process model of the experimental TEDS facility housed within the Energy Systems Laboratory at INL. The model was then used during the preconstruction phase of the experimental effort to inform experimental design (insulation requirements, bypass line placement, expected performance of components) and to test innovative control schemes prior to the initial operation. The TEDS model developed in Modelica includes the primary components of the TEDS experimental unit including: a $200 \mathrm{~kW}$ Chromalox heater, a single-tank packedbed thermal-energy storage system filled with 0.125 inch Alumina $\left(\mathrm{Al}_{2} \mathrm{O}_{3}\right)$ beads, an ethylene-glycol-to-therminol-66 heat exchanger, system piping, five control valves, and all associated temperature, pressure, and volumetric flow sensors. The model does not include nitrogen-fill gas tanks, or associated overfill tanks, as these are not part of standard system control.

Two simulation sets were run. The first was a 5-hour test that operates as a shakedown test for the facility. This simulation puts the facility through all five potential operating modes and showcases the ability of valving, control sensors, and component controllers to meet the system demands. The second case imposes a typical summer day demand on the system from a region with mixed commercial and residential electrical needs where the generator alone cannot meet peak demand but instead requires the thermal storage unit to act as a peaking unit. Over the course of the 15-hour discharge cycle, heat losses account for a heat drop of approximately $15^{\circ} \mathrm{C}$ in outlet temperature. Such heat losses would lead to a decrease in overall system efficiency and may lead to additional changes for such designs in the future, potentially including a topping heater.

Through commencement of this work, a systems-level model of TEDS with associated control systems, sensors, piping diameters, and component capabilities has been created. This model has been utilized in the pre-experimental phase to inform system design, insulation thicknesses, and potential control schemes to operate the system effectively and safely. Once TEDS begins operation, this model will be refined, tuned, and used for validation and verification purposes. 
Page intentionally left blank 


\section{CONTENTS}

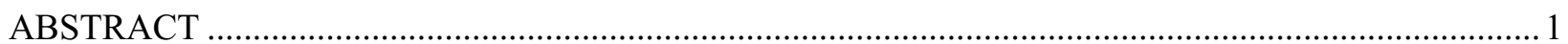

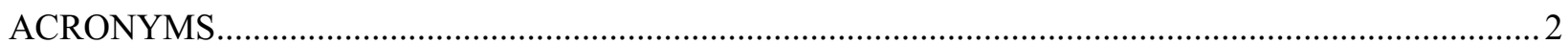

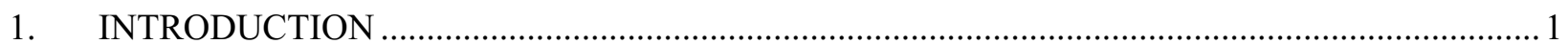

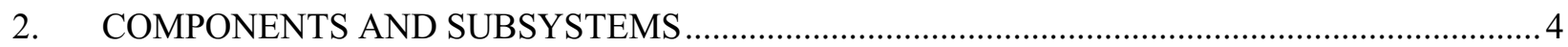

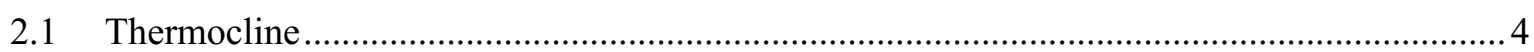

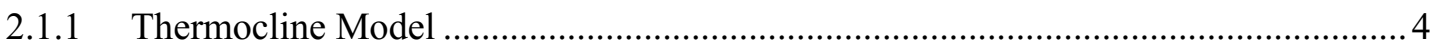

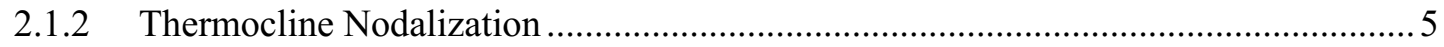

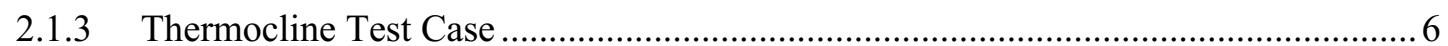

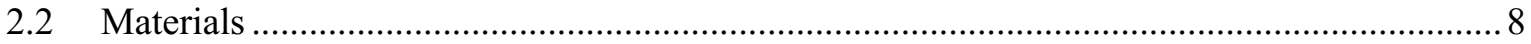

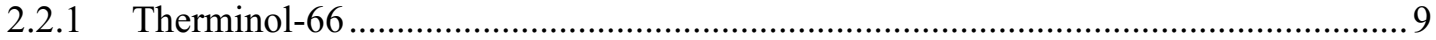

2.2.2 Ethylene Glycol (50\% water by Volume) …........................................................... 9

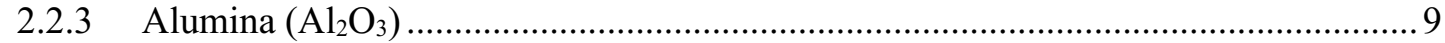

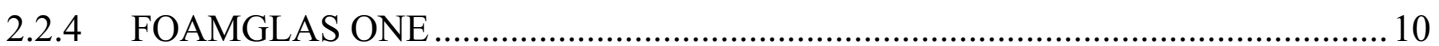

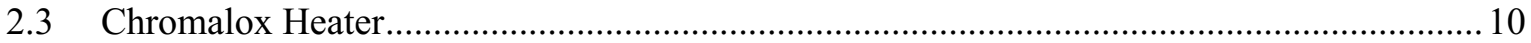

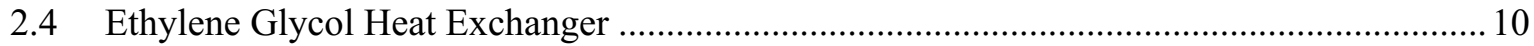

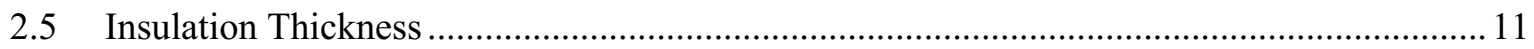

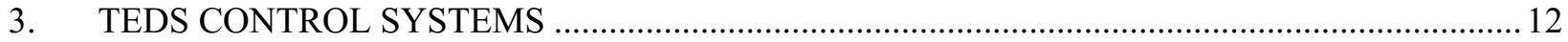

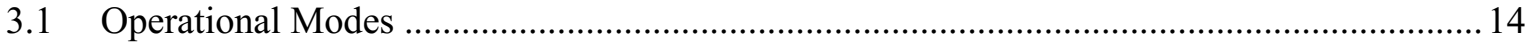

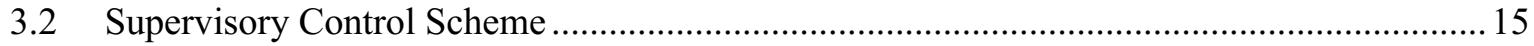

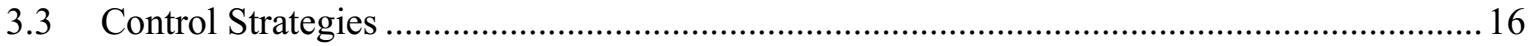

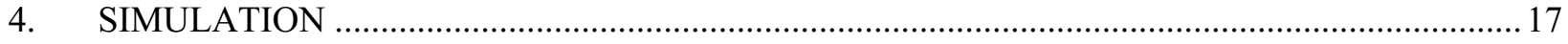

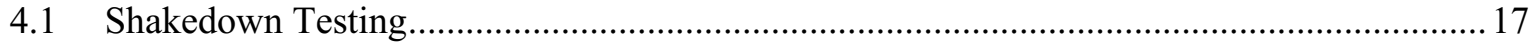

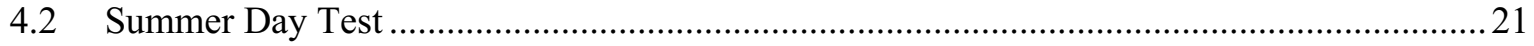

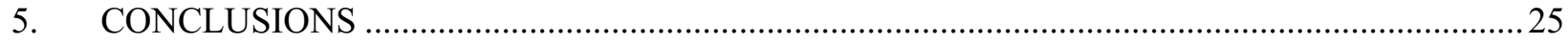

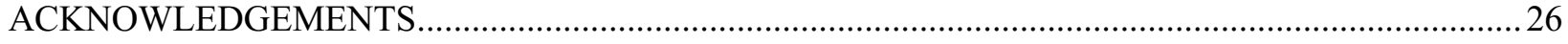

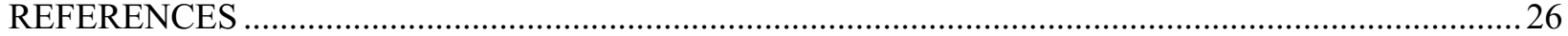


Page intentionally left blank 


\section{FIGURES}

Figure 1. Example architecture for Integrated Energy Systems........................................................... 1

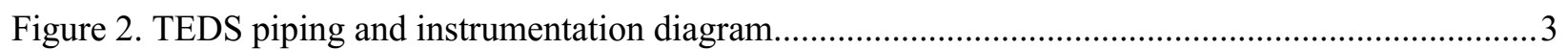

Figure 3. Nodal representation of thermocline model from Modelica. ...................................................... 5

Figure 4. Periodic charging and discharging thermocline test. ...................................................... 6

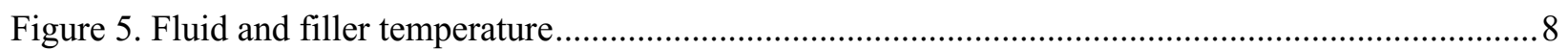

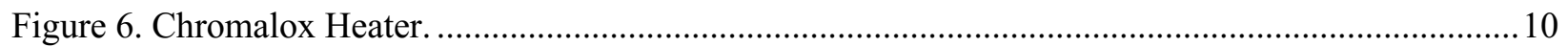

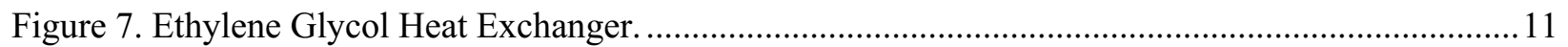

Figure 8. Thermocline Temperatures with varying levels of insulation................................................... 12

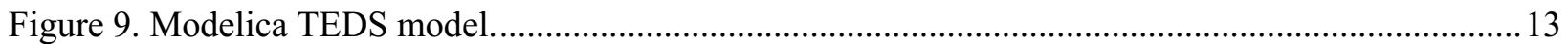

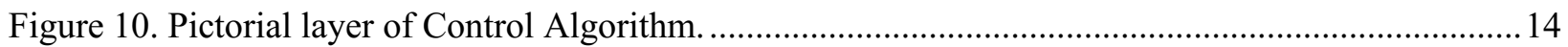

Figure 11. (Top) System demand on heater, thermocline, and total system. (Bottom) Thermocline fluid temperature at varying points within the tank. ............................................................... 19

Figure 12. (Top) Chromalox heater input. (Bottom) Temperatures throughout the TEDS loop. ..............20

Figure 13. (Top) Balance of plant mass flow rate. (Bottom) Thermal energy storage mass flow rates vs. sensor reading.

Figure 14. (Top) System demand on heater, thermocline, and total system. (Bottom) Thermocline

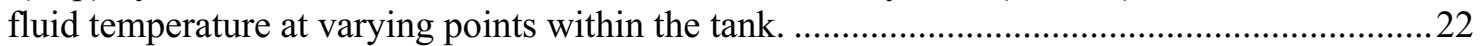

Figure 15. (Top) Chromalox heater input. (Bottom) Temperatures throughout the TEDS loop. ...............23

Figure 16. (Top) Balance of plant mass flow rate. (Bottom) Thermal energy storage mass flow rates vs. sensor reading......

\section{TABLES}

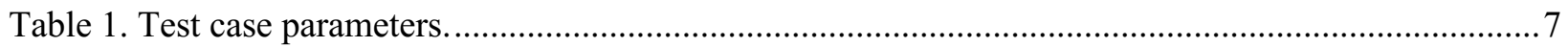

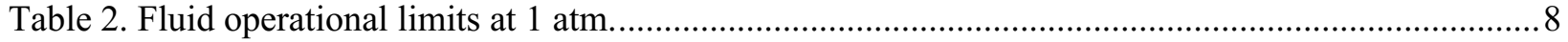

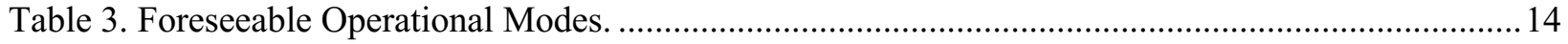

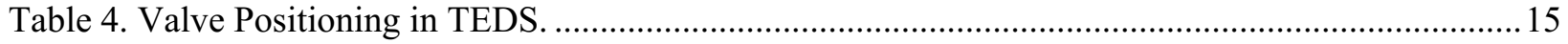

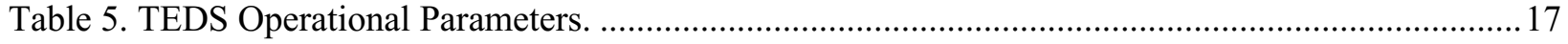

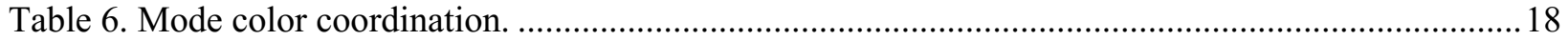


Page intentionally left blank 


\section{LIST OF ACRONYMS, INITIALISMS, AND ABBREVIATIONS}

BOP Balance of Plant

BV Ball Valve

DAE Differential Algebraic Equation

DETAIL Dynamic Energy Transport and Integration Laboratory

DNBR Departure from Nucleate Boiling Ratio

Dymola Dynamic Modeling Laboratory

FM Flowmeter

GBV Globe Valve

IES Integrated Energy Systems

INL Idaho National Laboratory

IPWR Integral Pressurized Water Reactor

IRIS International Reactor Innovative and Secure

LWR Light Water Reactor

M\&S Modeling and Simulation

ORNL Oak Ridge National Laboratory

PID Proportional Integral Derivative

PT Pressure Transducer

TC Thermocouple

TEDS Thermal Energy Distribution System

\section{Greek}

$a_{f} \quad$ Cross Sectional Area of Fluid

$C_{f} \quad$ Specific Heat of Fluid

$C_{r} \quad$ Specific Heat of Filler

$d_{r} \quad$ diameter of filler material

$\varepsilon \quad$ Porosity

$f_{s} \quad$ Surface Shape Factor

$h_{c} \quad$ Convective Heat-Transfer Coefficient

$h_{z} \quad$ Enthalpy

$k_{\text {fluid }} \quad$ Thermal Conductivity of the Fluid

$\dot{m} \quad$ mass flow rate

Pr Prandtl Number

$\rho_{f} \quad$ Density of Fluid 


$\begin{array}{ll}\rho_{r} & \text { Density of Filler } \\ q^{\prime \prime} & \text { Heat Flux } \\ \dot{Q}_{\text {losses }} & \text { Heat losses to ambient } \\ r_{\text {char }} & \text { Characteristic Radius } \\ r_{f i l l e r} & \text { radius of filler beads } \\ \mathrm{R} & \text { Radius of Tank } \\ \mathrm{Re} & \text { Reynolds Number } \\ S_{r} & \text { Heat-Transfer area of filler per unit length of the tank } \\ T_{f} & \text { Temperature of Fluid } \\ T_{r} & \text { Temperature of Filler } \\ U & \text { Average fluid velocity } \\ \mu_{f} & \text { Dynamic Viscosity of Fluid }\end{array}$




\section{INTRODUCTION}

Grid demand variability is an inherent part of the modern dynamic lifestyle. The addition of renewable energy technologies such as wind and solar introduces variability onto grid supply. As renewable integration continues, variability increases. The Integrated Energy Systems (IES) program, led by INL, is researching these effects. IES involve the design, integration, and coordinated operation of several complex, standalone systems. The control algorithms involved are unique to each application and the design of the components. IES architecture can include process steam applications, thermal-energy storage, and the presence of intermittent energy sources such as wind and solar, as shown in Figure 1.

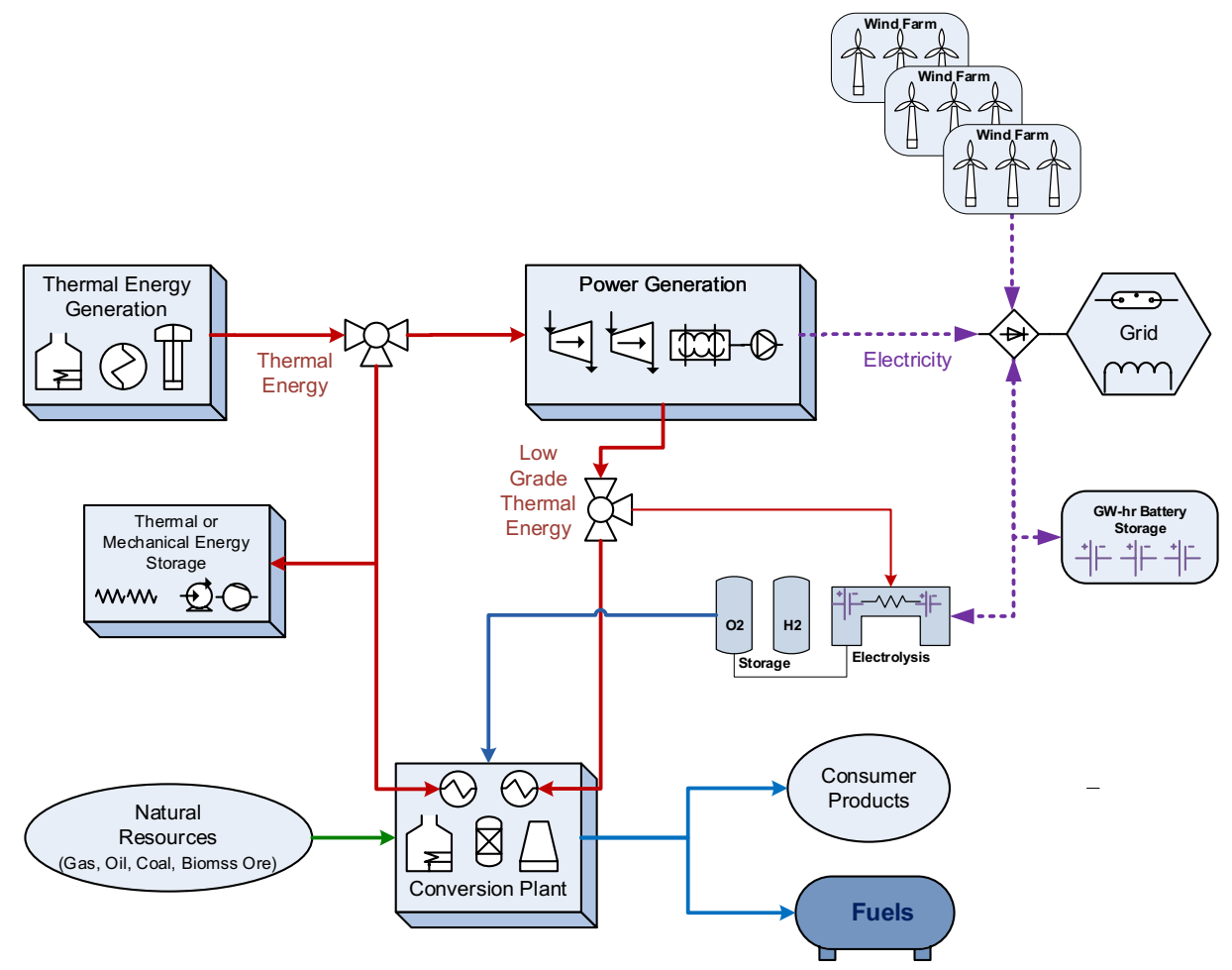

Figure 1. Example architecture for Integrated Energy Systems.

The goal of these systems is to operate as economically and efficiently as possible. For integrated energy parks that incorporate thermal storage, this means operating thermal generators at full power and storing excess energy for later use during times of low total demand and discharging that energy during times of high demand.

To accommodate the vast array of possibilities introduced in integrated energy parks, INL has been developing a library of high-fidelity process models in the Modelica modeling language since early 2013 [1-4]. The Modelica language is a non-proprietary, object oriented, equation-based language used to conveniently model complex, physical systems. Modelica is an inherently time-dependent modeling language that allows the swift interconnection of independently developed models. Being an equationbased modeling language that employs differential algebraic equation (DAE) solvers, users can focus on the physics of the problem rather than the solving technique, allowing faster model generation and, ultimately, analysis. This feature alongside system flexibility has led to the widespread use of the Modelica language across industry for commercial applications. System interconnectivity and the ability to quickly develop novel control strategies while still encompassing overall system physics is why INL has chosen to develop the IES framework in the Modelica language. 
Current models include thermal-energy storage, reverse osmosis, four-loop nuclear power plants, the IRIS reactor, natural gas turbines, coal plants, high-temperature steam electrolysis, and switchyards. The models are a cornerstone of the IES program at INL used to create and characterize system inertia, thermal losses, and efficiency of integrated systems. These physical models help map physical performance into economic performance, allowing system-level optimization. In addition, these models are used to test innovative system-level control strategies of interconnected thermal generators.

However, due to limited experimental data, the understanding of the interconnection between systems has been limited. To help address this lack in data and understanding, a Dynamic Energy Transport and Integration Laboratory (DETAIL) is being designed for installation within the Energy Systems Laboratory at INL to demonstrate integrated system operation. The overall objective for the DETAIL facility is to demonstrate simultaneous, coordinated, and efficient transient distribution of electricity and heat for power generation, energy storage, and industrial end-uses. The combined DETAIL facility will provide demonstration of real-time integration with the electrical grid, renewable energy inputs, thermal and electrical energy storage, and energy delivery to an end user. As such, an integrated energy network can be simulated to improve our understanding of how to optimize energy flows while maintaining system stability and efficient operation of all assets in the system.

A Thermal Energy Distribution System (TEDS), shown in Figure 2, acts as the backbone of the DETAIL facility to test heat-transfer components, distribution systems, instruments, and controls that can be monitored and controlled for hybrid generation of electrical power and/or non-electrical products. As is the case for other subsystems within DETAIL, TEDS is designed to operate either independently or as a part of an integrated system. Within the integrated system, TEDS will be connected to the INL Real-Time Power Simulation test platform to develop and demonstrate monitoring and control systems and to investigate real-time, hardware-in-the loop response characteristics relative to grid operations. The system can be used to characterize thermal-energy inertia and thermal-energy management relative to the interoperability of power generation, energy storage, and industrial heat applications. Further, TEDS operation will provide data to validate computational models such as RELAP, Modelica, and other transient physics-based models that can be used to support scale-up of hybrid energy systems for demonstration with operating (fueled) nuclear plants. TEDS can also be used to support cyber-informed engineering of controls and hardware systems.

To model control algorithms and elucidate potential problem areas, a TEDS model was developed in Modelica based upon initial design data. The TEDS model was implemented using the commercially available Modelica-based modeling and simulation (M\&S) environment (i.e., a Dynamic Modeling Laboratory [Dymola] version 2021) [5]. In-house-developed packages and open-source libraries were used to facilitate M\&S. In particular, the Modelica Standard Library version 3.2.3 [6] and TRANSFORM [7] from Oak Ridge National Laboratory (ORNL) were employed. This report provides an in-depth view to the Modelica model that will act as an informant to the experimental team prior to final installation and deployment, and later will serve as a verification and validation benchmark for the rest of the integrated energy system modeling efforts. 


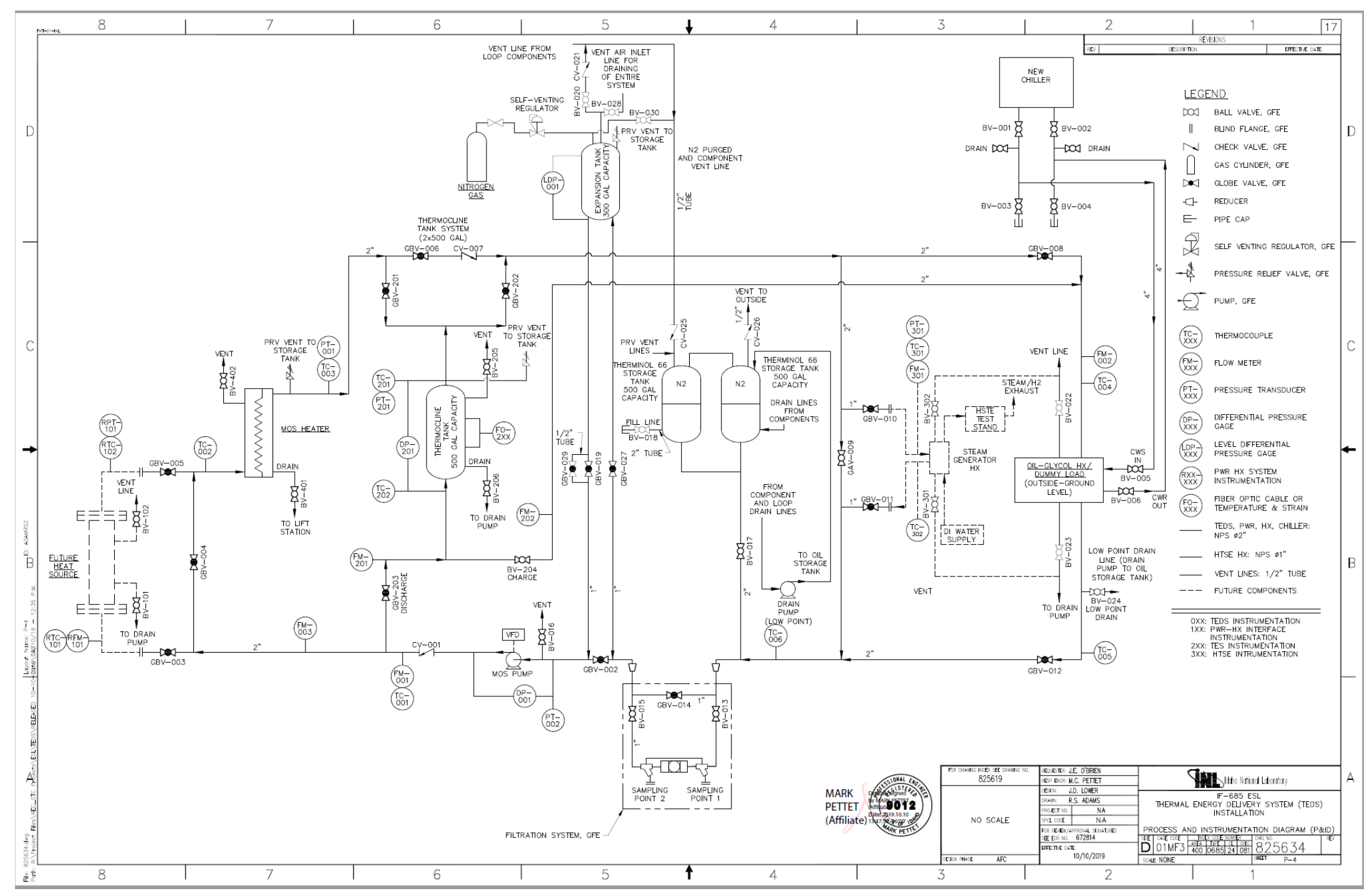

Figure 2. TEDS piping and instrumentation diagram. 


\section{COMPONENTS AND SUBSYSTEMS}

TEDS involves the culmination of several components and subsystems working in unison via control algorithms to ensure the proper transport of thermal energy throughout the system $[8,9]$. These subsystems and components include: a single-tank packed-bed thermocline, a Chromalox heater designed to simulate a thermal generator unit, an ethylene glycol heat exchanger, three materials to transfer heat around the system, and a series of insulated pipes to ensure proper redirection of flow and conservation of heat.

\subsection{Thermocline}

A major initial component of the TEDS system is the single-tank packed-bed thermocline system. This thermal-energy storage component can store $200 \mathrm{kWt}$ of thermal energy. A thermocline storage system stores heat via hot and cold fluid separated by a thin thermocline region that arises due to density differential between the fluid. Assuming low mixing via internal flow characteristics and structural design, this thermocline region can be kept relatively small in comparison with the size of the tank. Additionally, large buoyancy changes and low internal thermal conductivity are also extremely useful in maintaining small relative thermocline thickness.

To increase the cost-effective nature of these designs, it is common to fill the tank with a low-cost filler material, such as concrete or quartzite. These filler materials are cheap, have high density, and high thermal conductivity. By using such material, a reduction in the amount of high cost thermal fluid can be achieved, thereby increasing the economic competitiveness of such designs.

\subsubsection{Thermocline Model}

The thermocline system was modeled from a modified set of Schumann equations that were originally introduced in 1927 [10]. The equation set governs energy conservation of fluid flow through porous media. His equation set has been widely adopted in the analysis of thermocline storage tanks. The modified equations adopted a new version of the convective heat-transfer coefficient to incorporate low and no-flow conditions from Gunn in 1978 [11]. Additionally, a conductive heat-transfer term was added for the heat conduction through the walls of the tank. Self-degradation of the thermocline in the axial direction is neglected due to low relative values when during standard operation, this is a known limit of the model during times of no flow.

Energy Balance for the Fluid:

$$
\begin{gathered}
a_{f}=\varepsilon \pi R^{2} \\
\rho_{f} \varepsilon \pi R^{2} U\left(h_{z}-h_{z+d z}\right)+h_{c} S_{r}\left(T_{r}-T_{f}\right) d z+\dot{Q}_{\text {losses }}=\rho_{f} C_{f} \varepsilon \pi R^{2} d z \frac{\partial T_{f}}{\partial t} \\
U=\frac{\dot{m}}{\rho_{f} a_{f}} \\
S_{r}=\frac{f_{s} \pi R^{2}(1-\varepsilon)}{r_{\text {filler }}} \\
h_{c}=\left(\left(7-10 \varepsilon+5 \varepsilon^{2}\right)\left(1+0.7 \operatorname{Re}^{0.2} \operatorname{Pr}^{0.33}\right)+\left(1.33-2.4 \varepsilon+1.2 \varepsilon^{2}\right) \operatorname{Re}^{0.7} \operatorname{Pr}^{0.33}\right) \frac{k_{\text {fluid }}}{2 r_{\text {char }}} \\
\operatorname{Re}=\frac{4 r_{\text {char }} \dot{m}}{a_{f} \mu_{f}} \\
r_{\text {char }}=\frac{\varepsilon d_{r}}{4(1-\varepsilon)}
\end{gathered}
$$




\section{Energy Balance for the Rock:}

$$
h_{c} S_{r}\left(T_{r}-T_{f}\right) d z=-\rho_{r} C_{r}(1-\varepsilon) \pi R^{2} d z \frac{\partial T_{r}}{\partial t}
$$

\subsubsection{Thermocline Nodalization}

The thermocline system is split up into axial nodes, each of which incorporates a fluid and solid component. During charging mode, the flow runs from the hot side to the cold side, and in discharge mode, it runs in the opposite direction. The boundary conditions of each node depend on the direction of the flow and the advection of the previous nodes' values. For example, if the thermocline is operating in discharge mode, the node $\mathrm{N}-1$ will receive boundary values from node $\mathrm{N}-2$. While, if in charging mode, node N-1 will use boundary conditions from node N. A representation of the nodal split is illustrated in Figure 3.

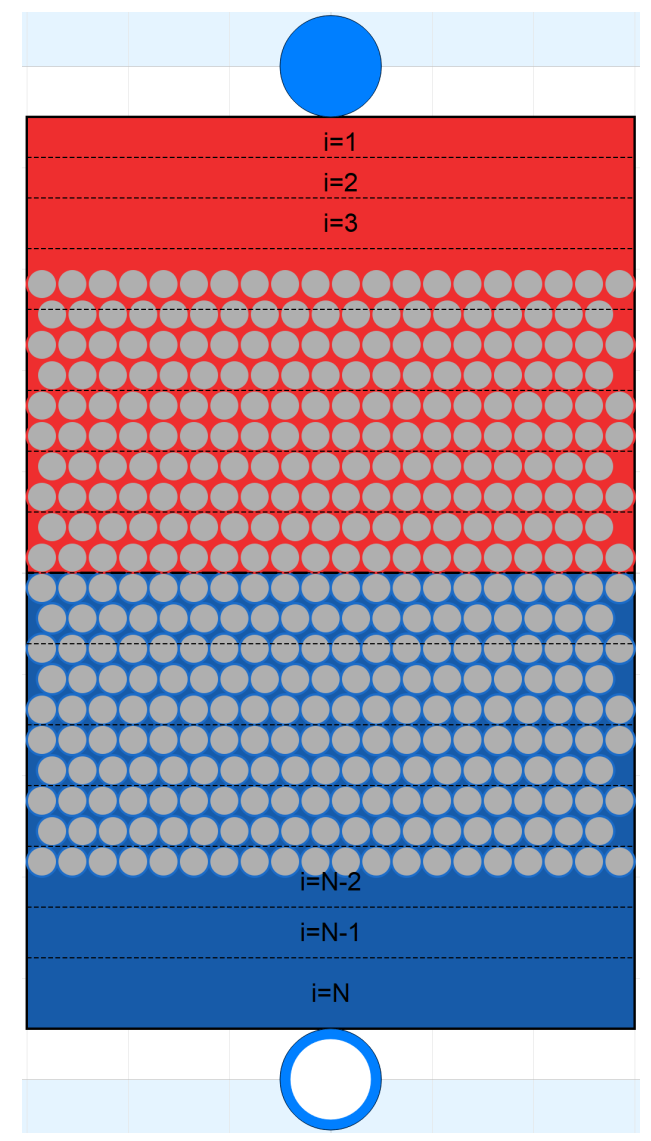

Figure 3. Nodal representation of thermocline model from Modelica.

In addition to the axial representation of heat distribution through a packed-bed porous medium, there exist radial temperature losses through the tank walls and insulation surrounding the tank to the ambient area surrounding the tank. To account for this loss, the simulation accounts for the heat loss surrounding the tank in each nodal fluid profile. Heat losses are calculated using Fourier's law of heat conduction $q^{\prime \prime}=-k \frac{d T}{d x}$ using built-in Modelica conduction models for cylinders. This heat is then spread over the entire the fluid volume at each axial position. This then interacts with the solid volume through standard convection in the energy balance for the filler. 


\subsubsection{Thermocline Test Case}

To demonstrate the ability of the model to properly charge and discharge through hourly and daily cycling, a periodic sample was conducted. System parameters are available in Table 1. Therminol-66 is the working fluid, and the filler material is Alumina beads with a total porosity of 0.6 , meaning the system is $40 \%$ Alumina beads by volume. To test charging and discharging capability an 8 -hour periodic cycle was imposed on the system. The first 4 hours are spent discharging the system and the next four are spent charging the system with hot therminol-66. This is illustrated in Figure 4. Figure 5 illustrates that the bottom of the tank quickly falls in temperature as the colder fluid comes in during discharge operation and starts to move up the tank. Toward the end of the initial 4 hours, the top of the thermocline tank begins to decrease in temperature as the thermal gradient begins to reach the top of the tank. It is at this point that the thermocline would no longer be a useful source of heat. Then, at hour 4, flow reverses and the tank begins to charge with hot fluid. As the hot fluid charges from the top, as opposed to entering from the bottom of the tank, the top node of $\mathrm{i}=1$ rises back up to $325^{\circ} \mathrm{C}$ as the hot fluid passes that position and moves down the tank. Initially, the bottom of the tank remains at the nominal value of $225^{\circ} \mathrm{C}$. However, toward the end of hour 4 , the bottom of the tank begins to increase in temperature as the thermal gradient begins to reach the bottom of the tank, at which point the tank is almost fully charged. Filler material follows the same pattern in each node as depicted in the bottom of Figure 5. These transient simulations are then repeated over the next 50+ hours and results do not vary as the tank is well insulated from the $0.2 \mathrm{~m}$ of fiberglass, despite the large ambient temperature difference. The filler material while being a large source of stored heat per volume causes an exacerbation of the thermocline as it conducts heat to the fluid. This can be seen at hour 8 where node 150 is not yet at the nominal inlet temperature, while node 200 is already being heated. This means the bottom quarter of the tank is a thermal gradient at that point and this is due to the lag in time for the filler to give up its heat as the thermocline passes by.

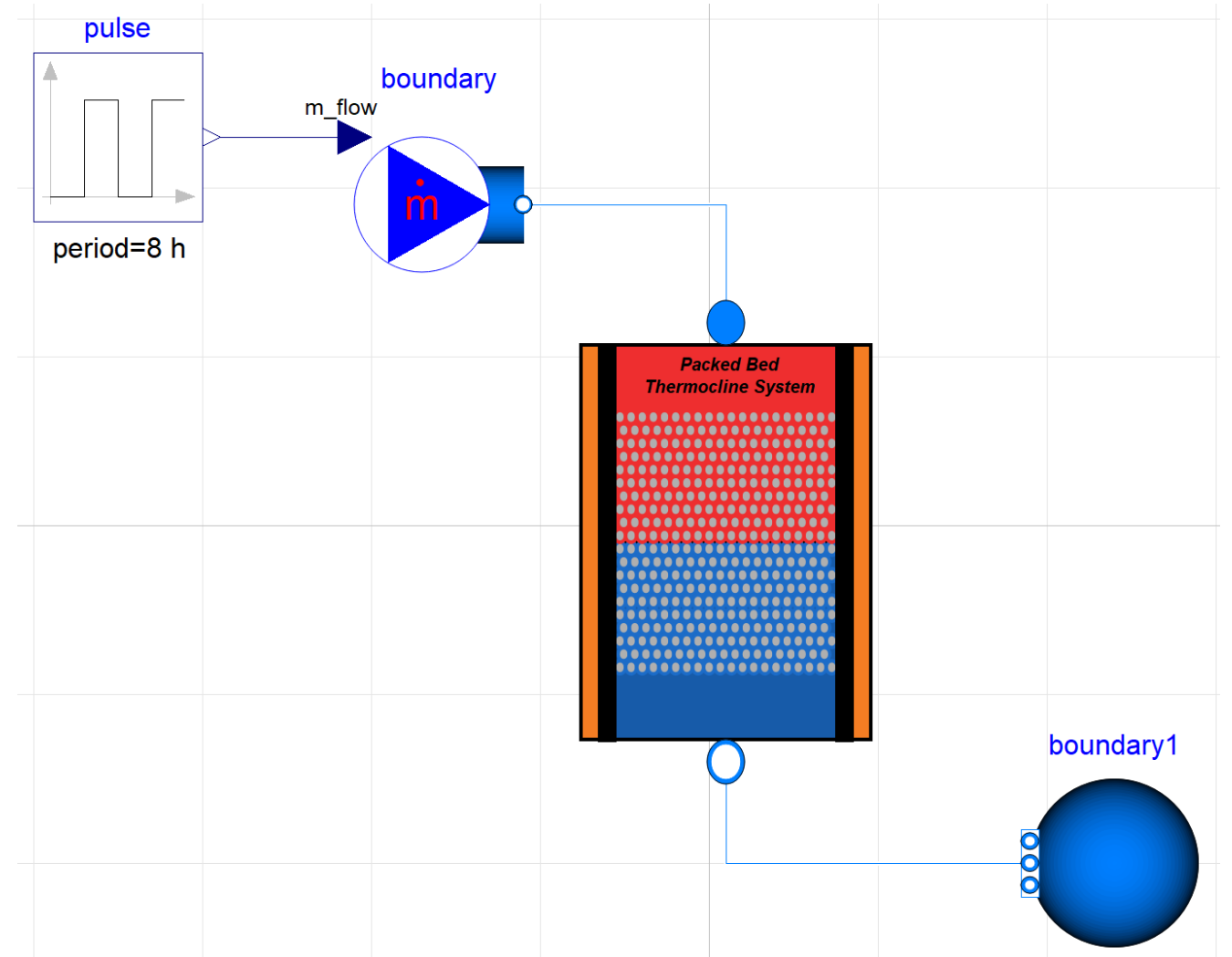

Figure 4. Periodic charging and discharging thermocline test. 
Table 1. Test case parameters.

\begin{tabular}{|l|l|}
\hline \multicolumn{1}{|c|}{ Parameter } & \multicolumn{1}{c|}{ Value } \\
\hline Fluid Material & Therminol-66 \\
\hline Filler Material & Alumina \\
\hline Wall Material & Stainless Steel \\
\hline Insulation Material & FiberGlass \\
\hline Porosity & 0.6 \\
\hline Tank Height & $14.6 \mathrm{~m}$ \\
\hline Tank Radius & $7.6 \mathrm{~m}$ \\
\hline Ambient Temperature & 20 Celsius \\
\hline Nodes & 200 \\
\hline Wall Thickness & $0.051 \mathrm{~m}$ \\
\hline Insulation Thickness & $0.204 \mathrm{~m}$ \\
\hline Charge Incoming Temperature & 325 Celsius \\
\hline Discharge Incoming Temperature & 225 Celsius \\
\hline
\end{tabular}



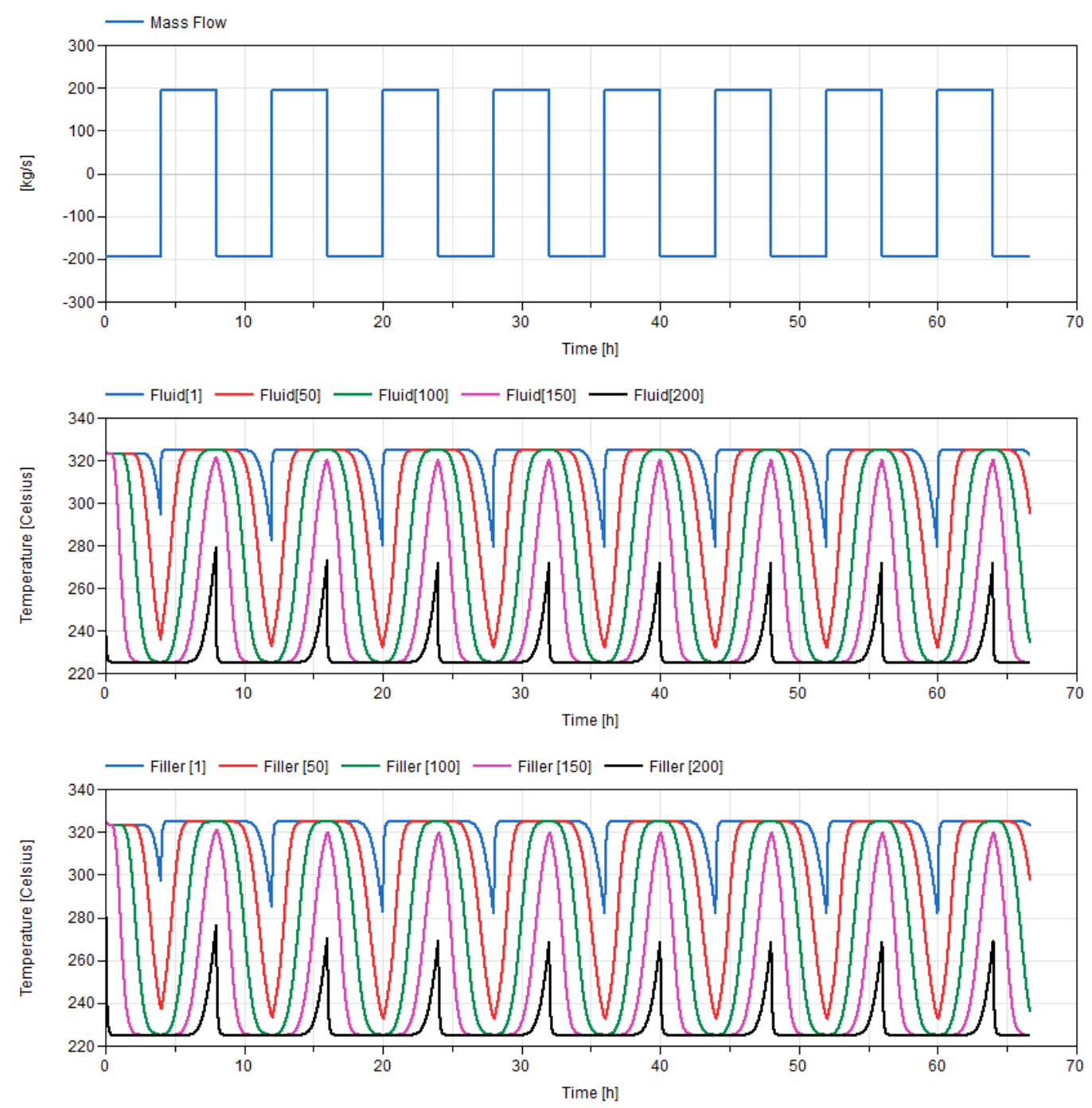

Figure 5. Fluid and filler temperature at axial locations of $i=1$ (top of tank), $i=50$ ( $25 \%$ down the tank), $\mathrm{i}=100$ (50\% down the tank), $\mathrm{i}=150$ (75\% down the tank), $\mathrm{i}=200$ (bottom of the tank.)

\subsection{Materials}

To correctly model the system, several new materials had to be implemented into Modelica: therminol-66, ethylene glycol, Alumina, and FOAMGLAS ONE (insulation). Operational Limits for therminol-66 and ethylene glycol are available in Table 2.

Table 2. Fluid operational limits at $1 \mathrm{~atm}$.

\begin{tabular}{|l|l|l|}
\hline \multicolumn{1}{|c|}{ Material } & \multicolumn{1}{|c|}{ Boiling Point } & \multicolumn{1}{c|}{ Operational Band } \\
\hline Therminol-66 & $358^{\circ} \mathrm{C}\left(678^{\circ} \mathrm{F}\right)$ & $-2.7^{\circ} \mathrm{C}$ to $343.3^{\circ} \mathrm{C}\left(27^{\circ} \mathrm{F}\right.$ to $\left.650^{\circ} \mathrm{F}\right)$ \\
\hline Ethylene Glycol $(50 \%$ by Vol. $)$ & $\sim 110^{\circ} \mathrm{C}\left(230^{\circ} \mathrm{F}\right)$ & $-30^{\circ} \mathrm{C}$ to $105^{\circ} \mathrm{C}\left(-22^{\circ} \mathrm{F}\right.$ to $\left.221^{\circ} \mathrm{F}\right)$ \\
\hline
\end{tabular}

To maintain library consistency each of these materials was added into the TRANSFORM library housed at ORNL under their pre-existing media package. 


\subsubsection{Therminol-66}

Therminol-66 is a heat-transfer fluid sold by Solutia (Eastman Chemical Company) that has been used in the chemical industry for heat-transfer applications for decades. Therminol-66 properties in Modelica are as follows [12].

$$
\begin{gathered}
\rho(T)\left[\frac{k g}{m^{3}}\right]=-0.000321 T^{2}-0.614254 T+1020.62 ; T \text { in Celsius } \\
\mu(T)[P a * s]=\rho(T) * \exp \left(\frac{586.375}{T+62.5}-62.5\right) \times 10^{-06} ; T \text { in Celsius } \\
k(T)\left[\frac{W}{m * K}\right]=-0.00000015 T^{2}-0.000033 T+0.118294 ; T \text { in Celsius } \\
c_{p}(T)\left[\frac{k J}{k g * K}\right]=0.0000008970785 T^{2}+0.003313 T+1.496005 ; T \text { in Celsius }
\end{gathered}
$$

In the calculation of therminol-66 properties, specific heat is calculated once at the average planned operational temperature and is assumed to be constant over that band with respect to temperature. This assumption greatly reduces the property solves used in Modelica as it avoids a large number of derivative solves in the continuous space. This assumption is reasonable if one chooses the average fluid temperature of operation and specific heat can be assumed linear over that span. All other properties are continuously updated.

\subsubsection{Ethylene Glycol ( $50 \%$ water by Volume)}

Ethylene Glycol Properties are as follows:

$$
\begin{gathered}
\rho(T)\left[\frac{\mathrm{kg}}{\mathrm{m}^{3}}\right]=-0.002435 T^{2}-0.338484 T+1082.287 ; T \text { in Celsius } \\
\mu(T)[P a * s]=-0.00001474 T^{3}+0.00474114 T^{2}-0.50420746 T+20.088 \times 10^{-03} ; T \text { in Celsius } \\
k(T)\left[\frac{W}{m * K}\right]=\left(8.9758 T \times 10^{-05}-1.3975 T^{2} \times 10^{-06}+0.23951\right) * 1.729577 ; T \text { in Celsius } \\
c_{p}(T)\left[\frac{J}{k g * K}\right]=\left(7.3219 T \times 10^{-04}+0.81485\right) * 4180 ; T \text { in Celsius }
\end{gathered}
$$

As with therminol-66, specific heat is calculated once at the average planned operational temperature and is assumed to be constant over that band with respect to temperature. All other fluid properties are continuously updated. Ethylene Glycol properties are taken from a mixture of sources $[13,14]$. The ethylene glycol used in the heat exchanger is assumed to be $50 \%$ by volume water and the properties shown above are consistent with this assumption.

\subsubsection{Alumina $\left(\mathrm{Al}_{2} \mathrm{O}_{3}\right)$}

Alumina Properties are as follows and based upon [15].

$$
\begin{gathered}
\rho(T)\left[\frac{\mathrm{kg}}{\mathrm{m}^{3}}\right]=3950 \\
k(T)\left[\frac{W}{m * K}\right]=5.85+15360 \exp \left(\frac{-0.002 T}{T+516}\right) ; T \text { in Celsius } \\
c_{p}(T)\left[\frac{J}{k g * K}\right]=1117+0.14 T-411 \exp (-0.006 T) ; T \text { in Celsius }
\end{gathered}
$$


The material properties were thoroughly tested inside the Modelica framework to ensure a matching of values with literature.

\subsubsection{FOAMGLAS ONE}

FOAMGLAS ONE properties for the insulating material are from [16].

$$
\begin{gathered}
\rho(T)\left[\frac{\mathrm{kg}}{\mathrm{m}^{3}}\right]=117 \\
k(T)\left[\frac{W}{m * K}\right]=2.59916 \times 10^{-07} T^{2}+1.40496 \times 10^{-04} \mathrm{~T}+0.0384688 ; T \text { in Celsius } \\
c_{p}(T)\left[\frac{\mathrm{J}}{\mathrm{kg} * K}\right]=770
\end{gathered}
$$

\subsection{Chromalox Heater}

The Chromalox heater was modeled as a multi-node pipe with the heat input equally distributed throughout as shown in Figure 6. The heater operates to maintain the temperature at "sensor_T1" at some nominal setpoint. This is controlled via a proportional integral derivative (PID) controller that ensures an equal heat input into each segment of the Chromalox heater. The heater is bounded to a maximum heater input according to vendor specifications. For terms of pressure loss calculations heater mass flow is assumed to be a fully developed and capable of operating in either the laminar the turbulent region depending on the Reynolds number of the pipe. Heat transfer into the pipe is assumed to be ideal since the heating elements are in direct contact with the fluid.

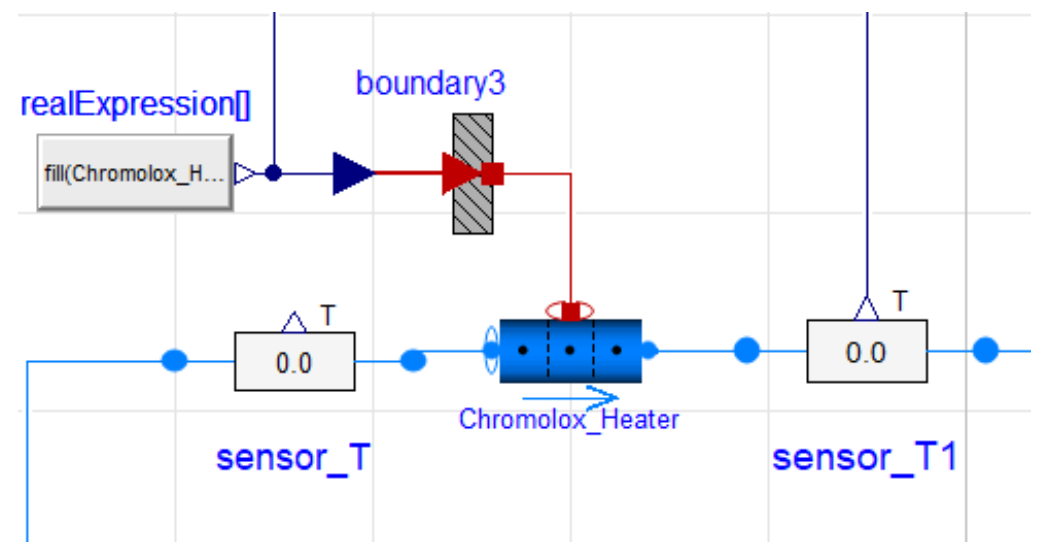

Figure 6. Chromalox Heater.

\subsection{Ethylene Glycol Heat Exchanger}

The ethylene glycol heat exchanger was modeled using the TRANSFORM heat exchanger model as a shell and tube heat exchanger with therminol-66 operating on the shell side of the heat exchanger and ethylene glycol on the tube side. Ethylene glycol flow rate flow operates via a flow control valve that attempts to ensure the therminol-66 temperature coming out of the heat exchanger is at a specified setpoint temperature. Tube material for the heat exchanger can be changed via a drop-down menu but has been specified as stainless steel 316 for TEDS. Heat exchanger on the tube side is calculated via the Dittus- Boelter correlation while heat transfer on the shell side is calculated via single phase two-region heat transfer where the correction factors are adjusted to meet predetermined heat-transfer characteristics. The heat exchanger setup is depicted in Figure 7. 


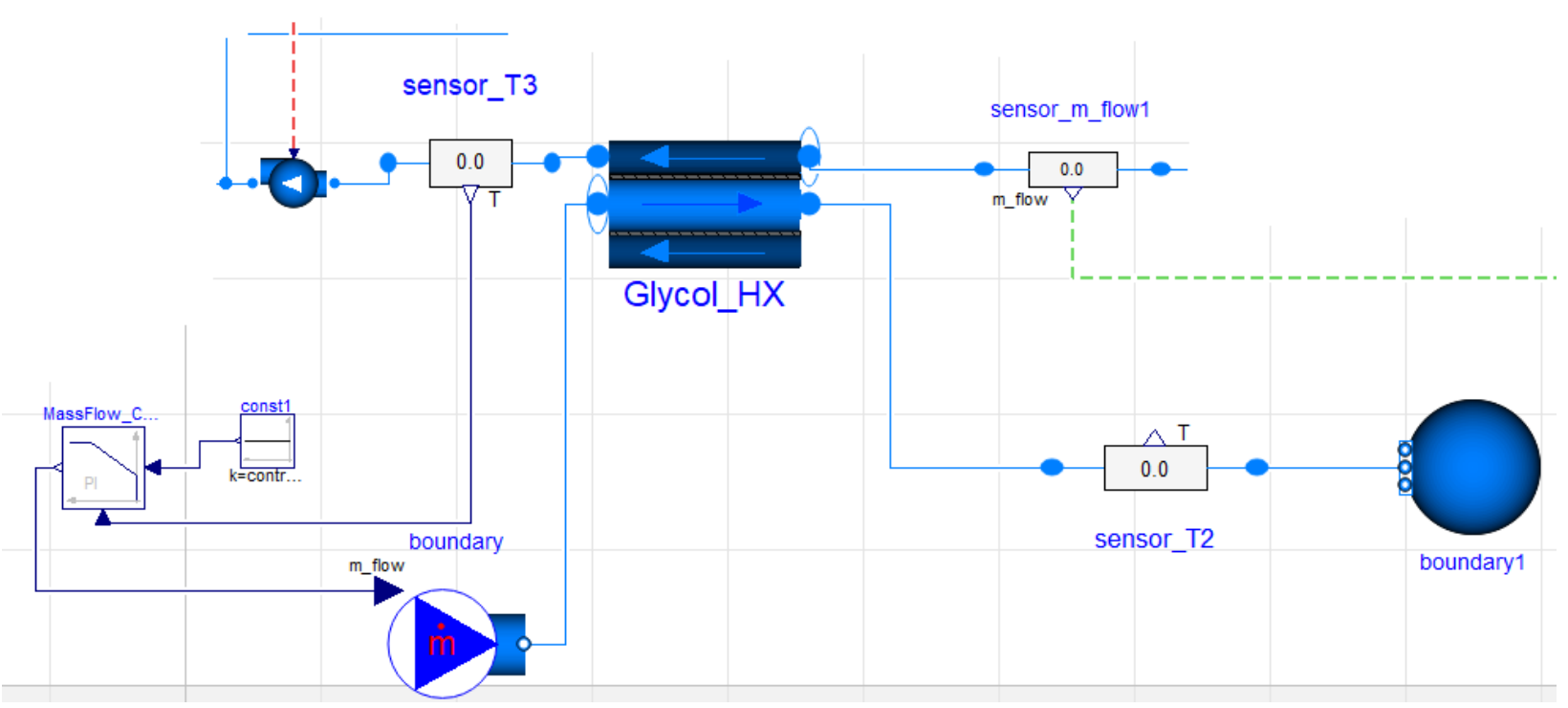

Figure 7. Ethylene Glycol Heat Exchanger.

\subsection{Insulation Thickness}

Assuming an infinitely wide tank, perfect insulation, or ambient temperatures equivalent to thermocline tank temperatures heat loss through the walls of the tank would not be a concern. Unfortunately, such conditions do not exist, and heat losses are a constant battle in thermal storage units. They are of even higher consequence in structures that present high relative surface area compared to internal volume. Due to size constraints within the experimental lab this is an omnipresent reality of the TEDS thermocline tank. Commercial entities that use thermocline tanks for chilled water storage have large diameters relative to system height and presents with relatively low thermal losses. However, TEDS has a large surface area relative to its volume, alongside a large temperature difference between the internal fluid and ambient surroundings. Therefore, the determination of insulation thickness needs is a trade-off between price, physical space to place the insulation, and heat losses. To decide on relative heat losses that are acceptable a simulation of temperature drop-off over a two-day period of inactivity, such as over a weekend, was conducted. Results are presented in Figure 8. 


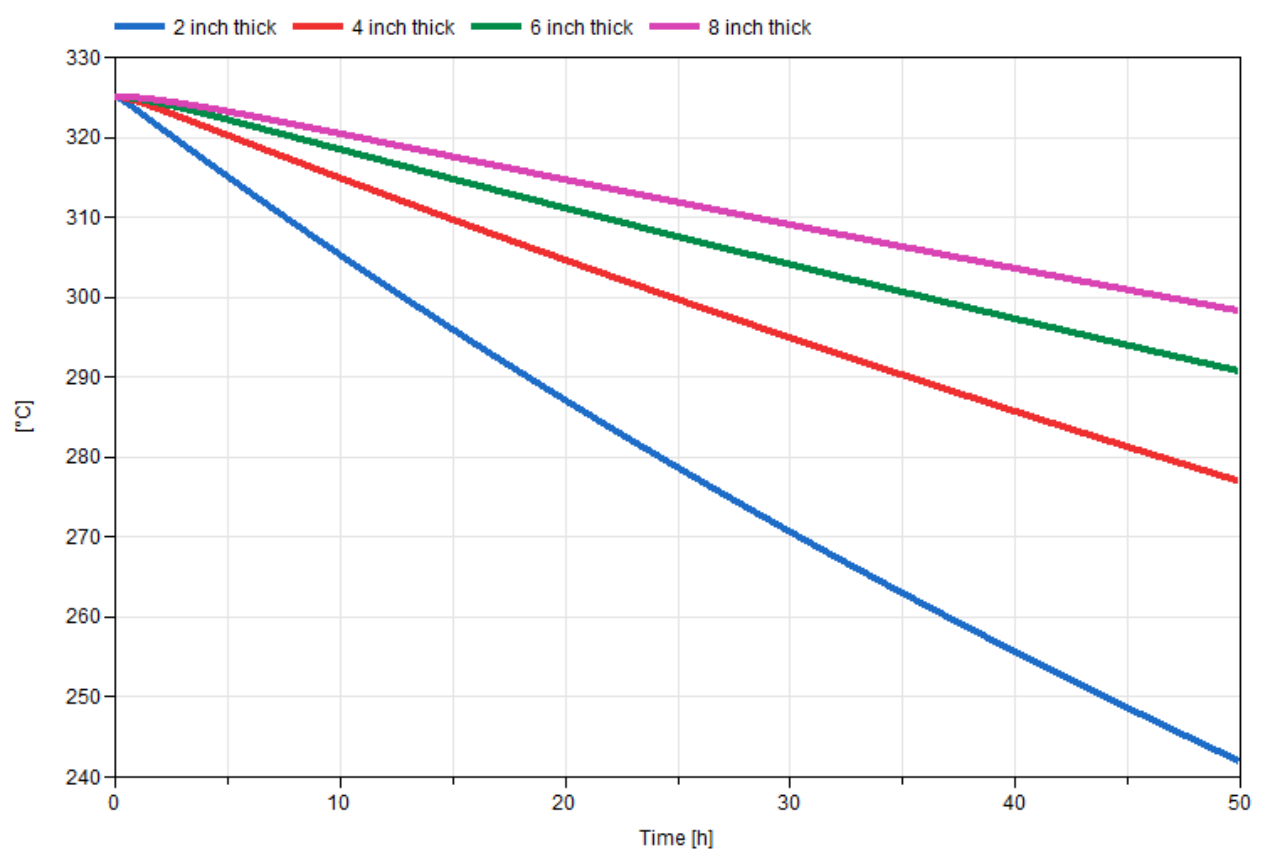

Figure 8. Thermocline Temperatures with varying levels of insulation.

The simulation assumes an initial thermocline temperature of $325^{\circ} \mathrm{C}$, consistent with a fully charged thermocline system. Flow is assumed stagnant. The simulation considers FOAMGLAS ONE insulation thicknesses of 2in, 4in, 6in, and 8in with it being known that 8inches is the upper bound of physical space surrounding the thermocline in which insulation could be placed. For the 2 -inch-thick insulation ambient heat losses would equate to $\sim 80^{\circ} \mathrm{C}$ drop in average tank temperature over the two days. Four-inch-thick insulation equated to a $47^{\circ} \mathrm{C}$ drop in the average temperature, while a six-inch-thick layer equated to a $33^{\circ} \mathrm{C}$ heat loss. Eight-inch-thick insulation was only modestly better at a $27^{\circ} \mathrm{C}$ drop over the two days. From this simulation it was determined that a six-inch layer of insulation would be the best trade-off in terms of effective storage of heat, while adequately fitting in the space surrounding the tank.

\section{TEDS CONTROL SYSTEMS}

In addition to the components discussed in the previous section a series of valves, sensors, and control algorithms is required to ensure all possible operation models are possible while maintaining component properties within acceptable limits of operation. A full schematic of the TEDS operational system in Modelica can be seen in Figure 9 and Figure 10. This section seeks to provide an in-depth description on the operational control schemes utilized in TEDS. For purposes of initial deployment, it is assumed the energy system consists of a heat generator, a thermal storage unit, and a heat sink that could be either a standard balance of plant or an ancillary process. 


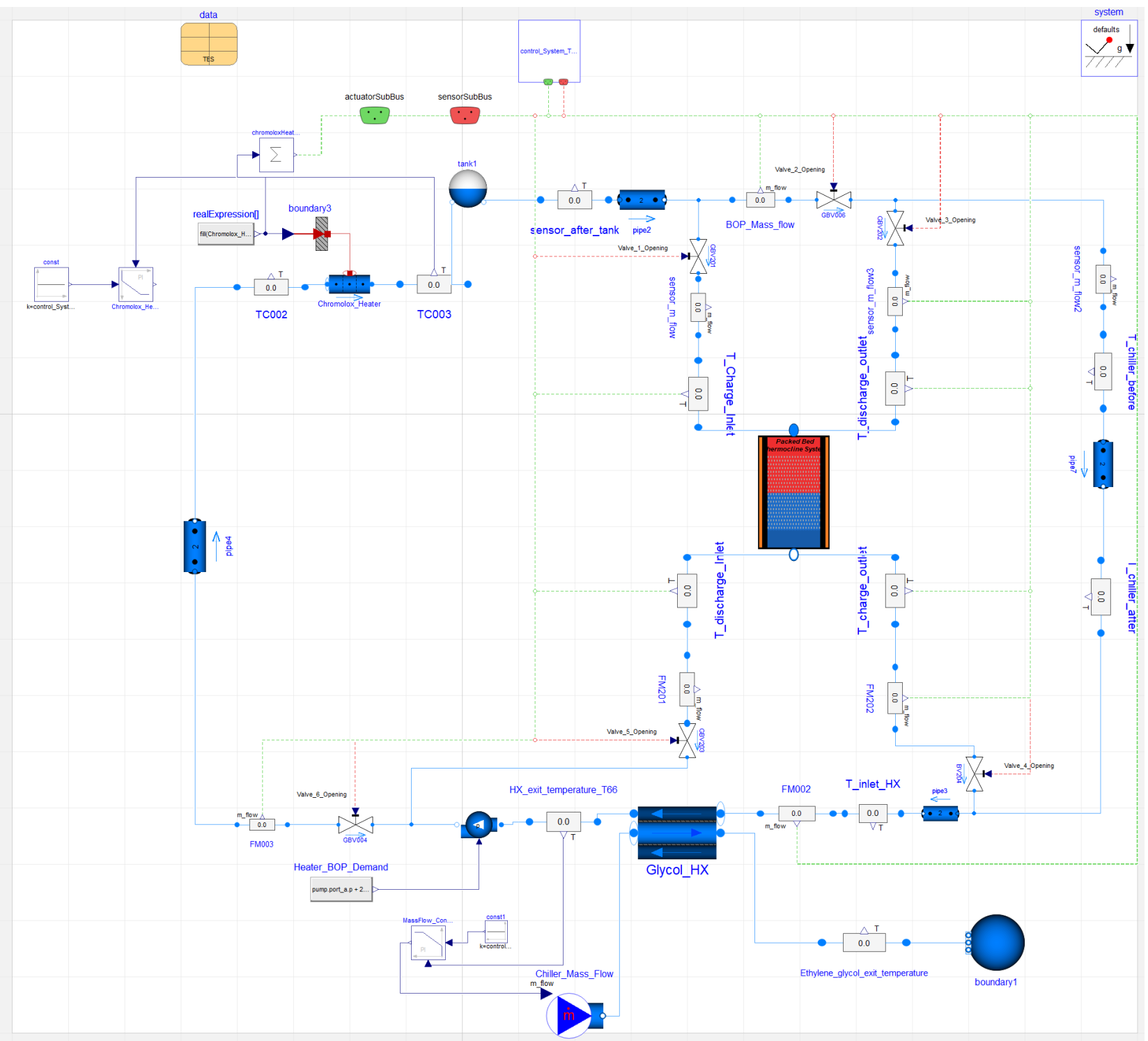

Figure 9. Modelica TEDS model. 


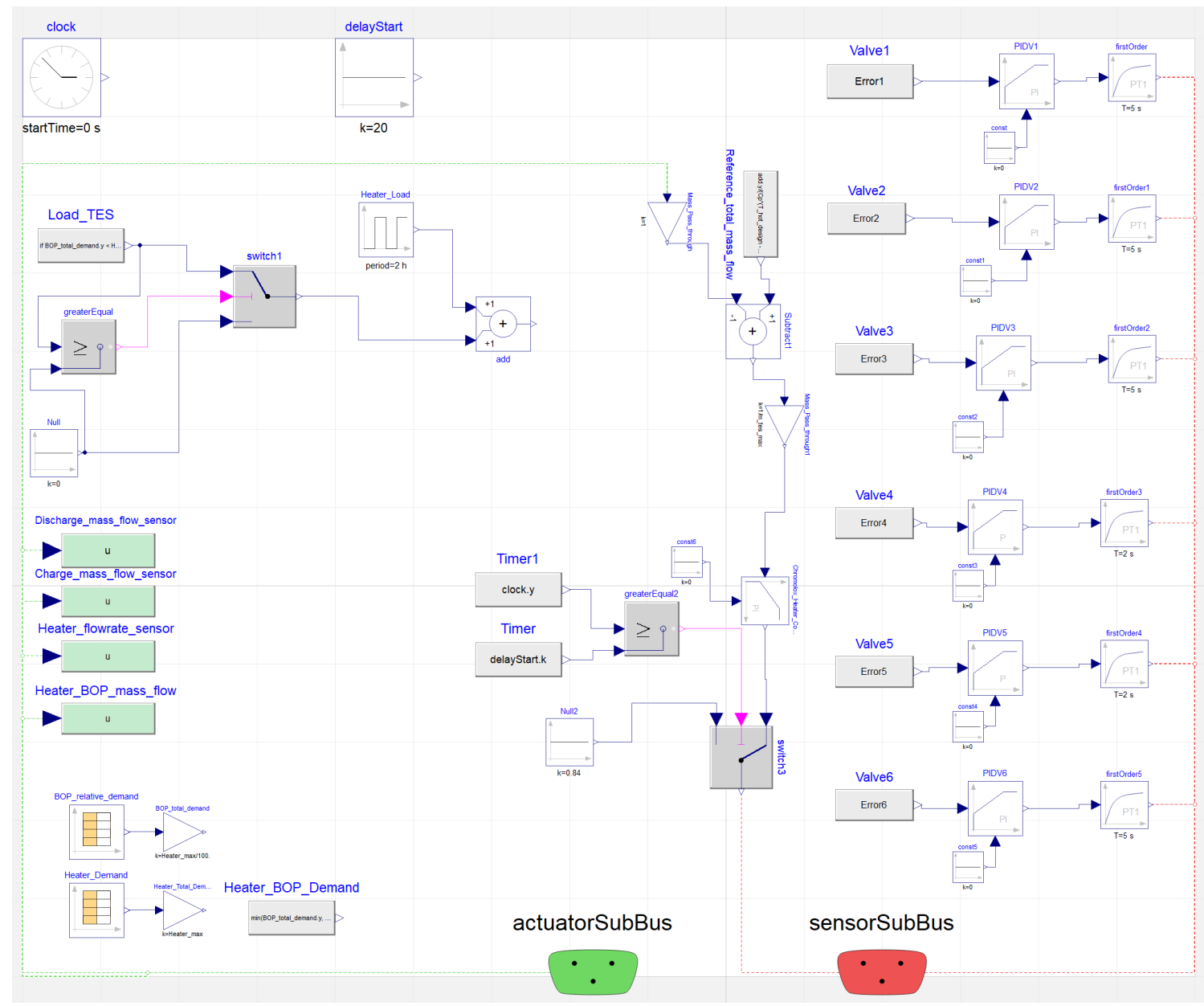

Figure 10. Pictorial layer of Control Algorithm.

\subsection{Operational Modes}

The TEDS project's dynamic flexibility is an inherent by-product of its potential to operate in several different modes. However, with increased flexibility comes increased complication in the form of control. To control the system, all foreseeable operating modes need to be accommodated with a single cohesive control strategy. In the initial deployment configuration, there are five possible operating modes each involving the thermal storage unit, depicted in Table 3.

Table 3. Foreseeable Operational Modes.

\begin{tabular}{|l|l|l|l|}
\hline \multicolumn{1}{|c|}{ Mode } & Heat source to Load & \multicolumn{1}{c|}{$\begin{array}{c}\text { Charging } \\
\text { (Heat source to thermocline) }\end{array}$} & \multicolumn{1}{c|}{$\begin{array}{c}\text { Discharging } \\
\text { (Thermocline to } \\
\text { Load) }\end{array}$} \\
\hline 1 & Yes & No & No \\
\hline 2 & No & Yes & No \\
\hline 3 & No & No & Yes \\
\hline 5 & Yes & Yes & No \\
\hline
\end{tabular}


Mode 1 simulates the heat generation source operating in standard operational mode with zero energy storage. This mode is akin to currently operating generators accommodating a standard load following mode. Mode 2 simulates a full charging scenario where the thermal generator is sending its heat to the thermal storage unit entirely. Mode 3 simulates a full discharge scenario. For this the thermal generator is turned off, and the thermal storage unit is the sole unit providing heat to the balance of plant or ancillary process. Mode 4 is a combination of modes 1 and 2 where the thermal generator is providing a portion of its heat to thermal storage and a portion to the heat load. Typically, this operational unit provides heat to the load first and then dumps excess heat into the thermal storage unit for use later. Mode 5 involves a combination of modes 1 and 3 where both the thermal generator and thermal storage tank are providing heat to the load. This operational modality would be common in an area that utilizes a large amount of intermittent renewable energy. For example, areas in the Midwest that rely heavily on wind energy. To appropriately accommodate these operating a combination of five valves are needed. Table 4 illustrates each valve's position in each mode. Note: Six valves appear in Figure 9 and Figure 10. However, GBV004 (valve 6) is an anticipated valve for future operations and remains fully open through all presented TEDS testing modalities.

Table 4. Valve Positioning in TEDS.

\begin{tabular}{|l|l|l|l|l|l|l|}
\hline \multicolumn{1}{|c|}{ Name } & \multicolumn{1}{|c|}{ Valve } & $\begin{array}{c}\text { Position } \\
\text { (Mode 1) }\end{array}$ & $\begin{array}{c}\text { Position } \\
\text { (Mode 2) }\end{array}$ & $\begin{array}{c}\text { Position } \\
\text { (Mode 3) }\end{array}$ & $\begin{array}{c}\text { Position } \\
\text { (Mode 4) }\end{array}$ & \multicolumn{1}{|c|}{$\begin{array}{c}\text { Position } \\
\text { (Mode 5) }\end{array}$} \\
\hline GBV-201 & 1 & Closed & Open & Closed & Open & Closed \\
\hline GBV-006 & 2 & Open & Closed & Closed & Open & Open \\
\hline GBV-202 & 3 & Closed & Closed & Open & Closed & Open \\
\hline BV-204 & 4 & Closed & Open & Closed & Open & Closed \\
\hline GBV-203 & 5 & Closed & Closed & Open & Closed & Open \\
\hline
\end{tabular}

Four of the five valves are strictly required to be fully controllable globe valves, while two can operate as ball valves. In practice the experimental team has made four of the valves globe valves in anticipation of operational modalities to come.

\subsection{Supervisory Control Scheme}

While the ability exists to impose bespoke demand signals to each individual system component it is important to consider markets scenarios that would impose each of the modes designed for the system. To incorporate this need, two separate market demand inputs are available for use: Heater power level and overall system demand. IES that include a thermal storage unit typically have the objective function of maximize profits or meet overall system demand depending on the market they operate in. In regulated markets the objective function is to meet overall system demand as cheaply as possible. In de-regulated markets the goal is to maximize system profits. In either scenario it is advantageous to operate your thermal generator, particular if it is nuclear, at full capacity and bypass excess steam into storage during either low pricing or demand and to discharge the thermal-energy storage unit during high prices or high demand. However, for purposes of refueling, maintenance, or excessively low demand/pricing there may times when the thermal generator will need to down power separate from the thermal storage unit. Therefore, two separate signals for overall demand and thermal generator power are available.

To determine the thermal storage demand, the following control logic is used.

$$
\operatorname{Load}_{T E S}(t)=\operatorname{Total}_{\text {Demand }}(t)-\operatorname{Heater}_{\text {Demand }}(t)
$$

Where,

$$
\begin{gathered}
\operatorname{Total}_{\text {Demand }}(t)=\text { Market }_{\text {Demand }}(t) \\
\operatorname{Heater}_{\text {Demand }}(t)=\text { Generator }_{\text {Decision }}(t)
\end{gathered}
$$


If $\operatorname{Load}_{T E S}(t)<0$ then excess capacity is to be sent to the thermal storage unit to be stored. If $\operatorname{Load}_{T E S}(t)>0$ then the thermal storage unit will begin discharge operation.

\subsection{Control Strategies}

To properly control the system for each mode the system needs to communicate a state variable to the centralized control unit. This is accomplished via mass, temperature, and flow sensors instrumented throughout the loop. The placement of these sensors is illustrated in Figure 2. Using these sensors, a control action can be taken in accordance with a desired overall system action. All controllers operate on a PI controller rather than a PID controller or simply a P control algorithm.

Valve 1: Globe valve (GBV-201) oscillates to meet a setpoint charging mass flow rate that is discerned off a reference load as shown, using flow meter (FM-202):

$$
\begin{gathered}
\dot{m}_{\text {chargingDemand }}=\frac{\left|\operatorname{Load}_{\text {TES }}\right|}{c_{\text {pavg }}\left(T_{\text {HotSP }}-T_{\text {ColdSP }}\right)} \text { if } \operatorname{Load}_{T E S}<0 \text {, else } 0 \\
\text { Error }_{1}=\frac{\dot{m}_{\text {chargingDemand }}-F M_{202}}{\dot{m}_{\text {chargingMax }}}
\end{gathered}
$$

Valve 2: GBV-006 oscillates to match a simulated balance of plant demand via a referred flow rate signal from FM-003 and FM-202.

$$
\begin{gathered}
\dot{m}_{\text {BOPDemand }}=\frac{B O P_{\text {Demand }}}{c_{\text {pavg }}\left(T_{\text {HotSP }}-T_{\text {ColdSP }}\right)} \\
\text { Error }_{2}=\frac{\dot{m}_{\text {BOPDemand }}-\left(F M_{003}-F M_{202}\right)}{\dot{m}_{\text {BOPMax }}}
\end{gathered}
$$

Valve 3: GBV-202 maneuvers to match the simulated discharge demand via signal from FM-201.

$$
\begin{gathered}
\dot{m}_{\text {dischargeDemand }}=\frac{\operatorname{Load}_{T E S}}{c_{\text {pavg }}\left(T_{\text {HotSP }}-T_{\text {ColdSP }}\right)} \text { if } \operatorname{Load}_{T E S}>0 \text {, else } 0 \\
\text { Error }_{3}=\frac{\dot{m}_{\text {dischargeDemand }}-F M_{201}}{\dot{m}_{\text {dischargeMax }}}
\end{gathered}
$$

Valve 4: BV-204 operates on an interlock system with GBV-201. The interlock system operates with a five second opening delay to ensure the charging and discharge lines cannot both be open simultaneously. In the event charging demand goes to zero, BV-204 will move to the full close position blocking all flow in the charge line. If demand is above zero, BV-204 will wait five seconds, allowing time for the discharge line to fully close and then it will move to the full open position.

Valve 5: GBV-203 operates in the same manner but for the discharge line. It is on an interlock system with GBV-202. In the event discharge demand is greater than zero, GBV-202 will begin to open, while GBV-203 remains closed for five seconds past when GBV-203 begins to open to ensure the charging line is fully closed prior to discharge operation.

Chromalox Heater: The Chromalox heater varies heater input to match a reference setpoint exit temperature out of the heater with TC-003. With a maximum heater input of $200 \mathrm{~kW}$. It is assumed this heat is input equally along the length of the heater and heater input can be controlled continuously.

$$
\text { Error }_{\text {Heater }}=T_{\text {Setpoint }}-T C_{003}
$$

If the temperature from TC-003 is below the temperature setpoint heater input will increase. Conversely, if TC-003 is higher than the setpoint temperature heater input will reduce. 
Chiller: The ethylene glycol chiller modulates coolant mass flow to maintain therminol-66 exit temperature at a setpoint temperature based on signal coming from TC-005.

$$
\text { Error }_{\text {chiller }}=T C_{005}-T_{\text {Setpoint }}
$$

If the setpoint temperature is cooler than TC-005, then coolant mass flow will increase causing more heat transfer from the therminol-66, thus decreasing outlet temperature. Alternatively, if the setpoint temperature is hotter than the TC-005 then, coolant mass flow decreases, this lowers the amount of heat transfer across the tubes and therminol-66 exit temperature rises. In addition to this control methodology a minimum mass flow constraint was placed on coolant flow to ensure coolant boiling does not occur. This constraint means that during times of low therminol-66 flow or low inlet temperature on the therminol-66 side a decrease in exit temperature will occur despite the error signal signaling to lower mass flow rate. This constraint ensures the ethylene glycol will not begin to boil and foul the heat exchanger. Construction of a bypass line on the therminol-66 side is in the works to eliminate this need and would allow the minimum flow rate requirement to be eliminated.

Pump: The TEDS pump's speed is controlled by a variable frequency drive to ensure a constant discharge pressure. Under normal operation this guarantees a sufficient driving force for the system valving configuration to operate in all foreseeable modes. Furthermore, if all valves in the system close, this ensures a system over-pressurization does not occur as the pump is operating to maintain a set exit pressure rather than a mass flow rate.

\section{SIMULATION}

This section provides an in-depth look at the capability of TEDS to handle different operational scenarios and how the performance would look according to experimental design sizing. For this two simulation sets were run. The first is a five-hour test that operates as a shakedown test for the facility. This simulation puts the facility through all five potential operating modes and showcases the ability of valving, control sensors, and component controllers to meet the system demands. The second case is imposing a typical summer day demand on the system from a region with mixed commercial and residential electrical needs where the generator alone cannot meet peak demand but instead requires the thermal storage unit to act as a peaking unit.

\subsection{Shakedown Testing}

To illustrate operation through the different modes of operation for TEDS a test case was input that could illustrate all five modes. For this simulation operational parameters are available in Table 5. Simulation results are available in Figure 11-Figure 13. Since the Chromalox heater has a maximum output capacity of $200 \mathrm{~kW}$ it is necessary to leave some margin under standard operation to allow for a power demand increase from the minimum flow rate condition mentioned earlier. Therefore, for purposes of this simulation $175 \mathrm{~kW}$ output is nominal full power. Once a bypass line is installed in the TEDS system this requirement will be eliminated.

Table 5. TEDS Operational Parameters.

\begin{tabular}{|l|l|}
\hline \multicolumn{1}{|c|}{ Parameter } & \multicolumn{1}{c|}{ Value } \\
\hline Fluid Material & Therminol-66 \\
\hline Filler Material & Alumina \\
\hline Wall Material & Stainless Steel 304 \\
\hline Insulation Material & FOAMGLAS $\AA$ ONE \\
\hline Porosity & 0.5 \\
\hline Filler Diameter & $0.00317 \mathrm{~m}(1 / 8$ in $)$ \\
\hline Tank Height & $4.435 \mathrm{~m}$ \\
\hline
\end{tabular}




\begin{tabular}{|l|l|}
\hline \multicolumn{1}{|c|}{ Parameter } & \multicolumn{1}{c|}{ Value } \\
\hline Tank Radius & $0.438 \mathrm{~m}$ \\
\hline Ambient Temperature & 20 Celsius \\
\hline Nodes & 200 \\
\hline Wall Thickness & $0.019 \mathrm{~m}$ \\
\hline Insulation Thickness & $0.153 \mathrm{~m}(6 \mathrm{in})$ \\
\hline Charge Incoming Temperature & $325^{\circ} \mathrm{C}$ \\
\hline Discharge Incoming Temperature & $225^{\circ} \mathrm{C}$ \\
\hline Maximum Heater Power & $200 \mathrm{~kW}$ \\
\hline Nominal Full Heater Output & $175 \mathrm{~kW}$ \\
\hline
\end{tabular}

The simulation starts with the thermal storage unit at $225^{\circ} \mathrm{C}$ as if in a fully discharged state. An initialization phase occurs for the first 300 seconds of the simulation. Then, up until the 30-minute mark, the simulation is running in operation mode 1 . Mode 1 has zero involvement with the thermal storage unit and instead simulates a steady load on the thermal generator from the balance of plant. Nominal mass flow rate throughout the TEDS loop is $0.735 \mathrm{~kg} / \mathrm{s}$ with a nominal power input of $175 \mathrm{~kW}$ from the heater, as illustrated in Figure 11, Figure 12, and Figure 13. At the 30-minute mark, total balance of plant demand begins to decrease while heater demand remains constant, signaling the charging operation to begin and an operational switch to mode 4 .

Table 6. Mode color coordination.

\begin{tabular}{|l|l|}
\hline Mode & Color \\
\hline 1 & \\
\hline 2 & \\
\hline 3 & \\
\hline 4 & \\
\hline 5 & \\
\hline
\end{tabular}

Mode 4 begins as BV-204 is signaled to open and GBV-201 modulates to send a reference setpoint mass flow to thermal-energy storage, allowing mass flow through that entire line. Simultaneously, GBV006 modulates to decrease mass flow to the dummy load. During this operation mode, the chiller is able to maintain exit temperature of therminol- 66 at the $225^{\circ} \mathrm{C}$ setpoint temperature, as seen in Figure 12.

However, as the mass flow sent to the dummy load decreases, ethylene glycol mass flow decreases, thus increasing the shell-side exit temperature. After 30 minutes in mode 4, dummy demand decreases to zero, and a mode switch to mode 2 occurs. 

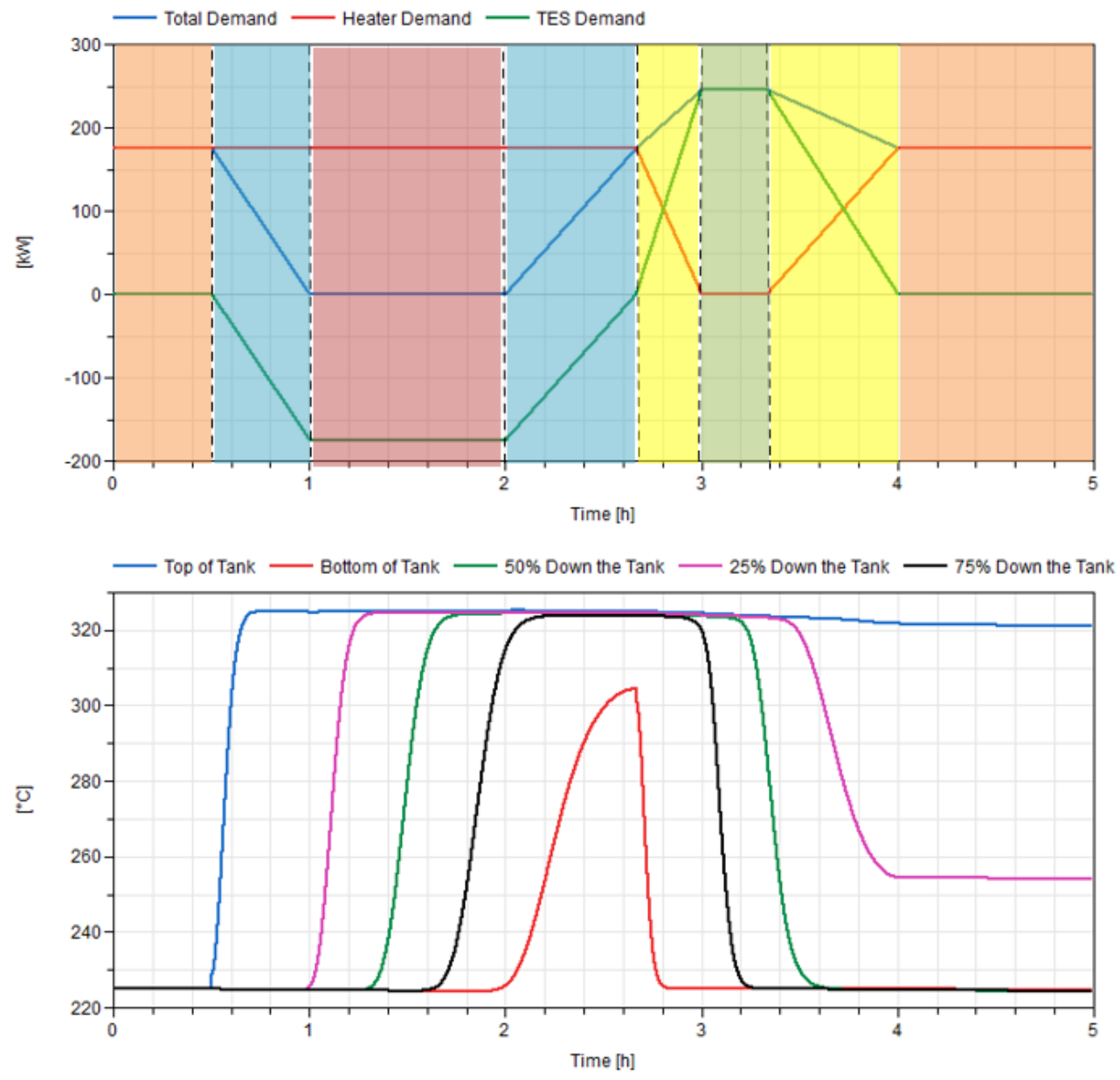

Figure 11. (Top) System demand on heater, thermocline, and total system. (Bottom) Thermocline fluid temperature at varying points within the tank.

In mode 2, there is no dummy load. Instead, all the heater load is sent to the thermal storage unit for later use. During mode 2 operation, the inlet temperature of the chiller is equal to the cold temperature in the thermal storage tank, this temperature is at or below the setpoint exit temperature of the chiller heat exchanger. This causes the ethylene glycol mass flow demand to fall to zero. If this were allowed the glycol would begin to boil at $120^{\circ} \mathrm{C}$, causing system fouling and degradation. Instead, a minimum mass flow rate limit of $0.05 \mathrm{~kg} / \mathrm{s}$ was maintained leading to a glycol exit temperature of $\sim 83^{\circ} \mathrm{C}$. This minimum mass flow limit subsequently dropped the therminol-66 exit temperature to $217.1^{\circ} \mathrm{C}$. Because the TEDS mass flow rate remains constant throughout this, the heater begins to operate at a higher power output $(\sim 190 \mathrm{~kW}$ compared to $175 \mathrm{~kW})$ to ensure an exit temperature of $325^{\circ} \mathrm{C}$. If a bypass line were utilized, this power increase would not be necessary. Mode 2 operation continues for an hour, charging the thermocline to $\sim 75 \%$ capacity based on thermocline position seen in Figure 11.

At hour 2, dummy demand increases, causing GBV-006 to open, moving the system back into operational mode 4 . Forty minutes into hour 2, total demand increases above heater demand, signaling discharge operation for the thermal storage unit and an operational switch to mode 5. As demand for the thermal storage unit moves from charging to discharge, several control actions occur. First, as $\dot{m}_{\text {chargingDemand }}$ goes to zero, BV-204 begins to close, as does GBV-201. Once BV-204 closes, a 10second delay is instantiated on GBV-203. During the delay, it cannot open nor can it be opened if BV-204 is open. This ensures an elimination of potential backflow through these lines and additionally ensures 
both charging and discharge modes cannot operate simultaneously. Once this 10-second delay is fulfilled, GBV-203 opens and GBV-202 begins modulating to allow the proper amount of mass flow through the discharge line. During this operational mode, ethylene glycol mass flow increases through the chiller to maintain the exit setpoint temperature. GBV-006 modulates as before to maintain BOP heater demand mass flow-through, while GBV-202 works to meet discharge mass flow requirements. The main system pump works to maintain a constant $\mathrm{dP}$ and, as such, must increase system mass flow.
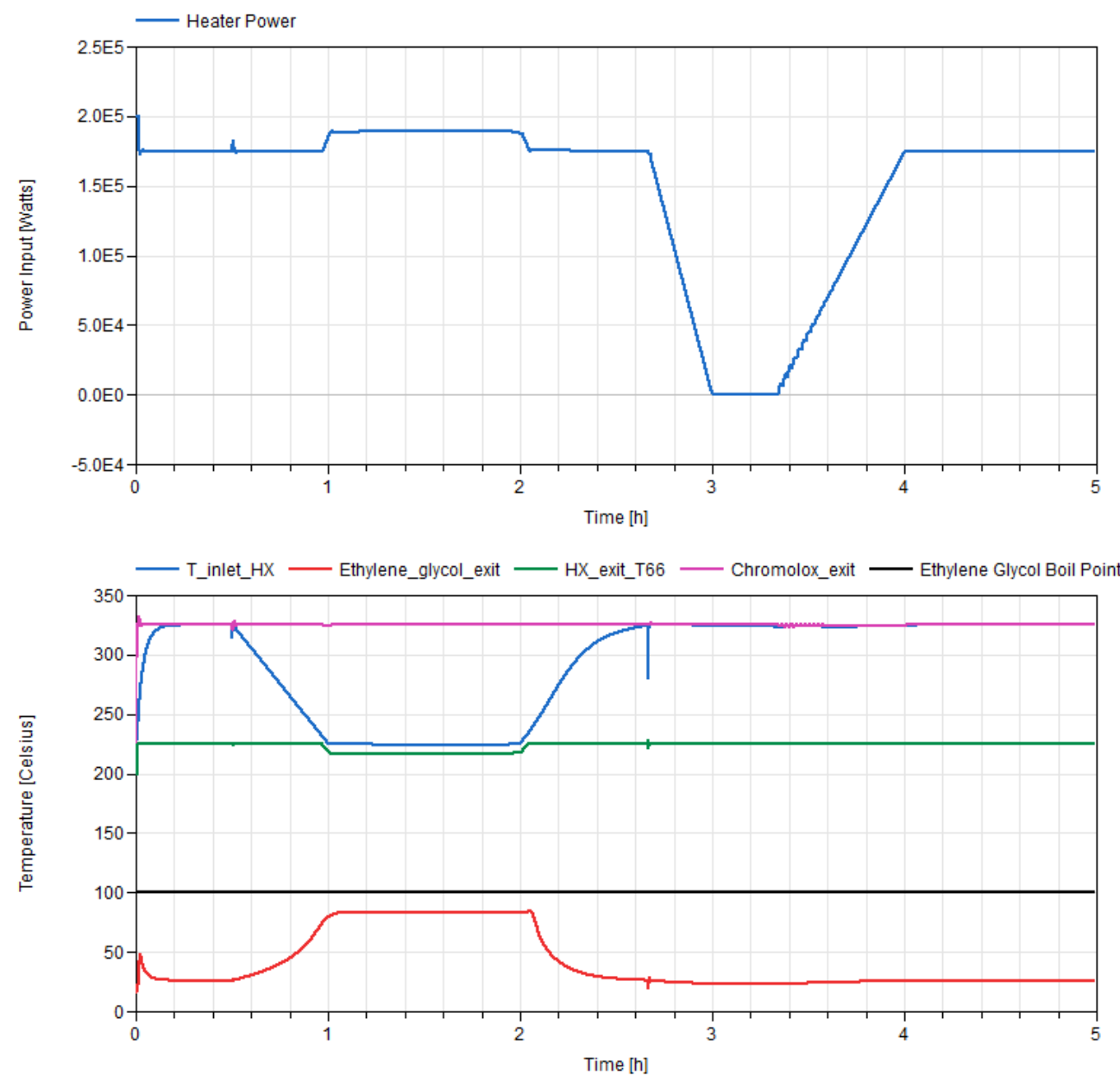

Figure 12. (Top) Chromalox heater input. (Bottom) Temperatures throughout the TEDS loop.

At hour 3, heater demand falls to zero, causing an operational switch to mode 3 . During mode 3 operation, only the thermal storage unit is providing heat to the balance of plant. Heater power input falls to zero as exit temperature remains at $325^{\circ} \mathrm{C}$ during stagnant flow operation. The thermal storage unit begins to discharge more quickly as it is fulfilling the entire system demand. Twenty minutes into hour 3, heater demand rises above zero and the system falls back into operational mode 5 . By the end of hour 4, system demand heater and heater demand are equal. This causes the thermal storage unit to close both charging and discharge lines, and operation mode 1 resumes. By the end of hour 3 , the thermal storage unit is almost entirely drained of useful energy as the discharge temperature begins to fall, as seen in Figure 11. 

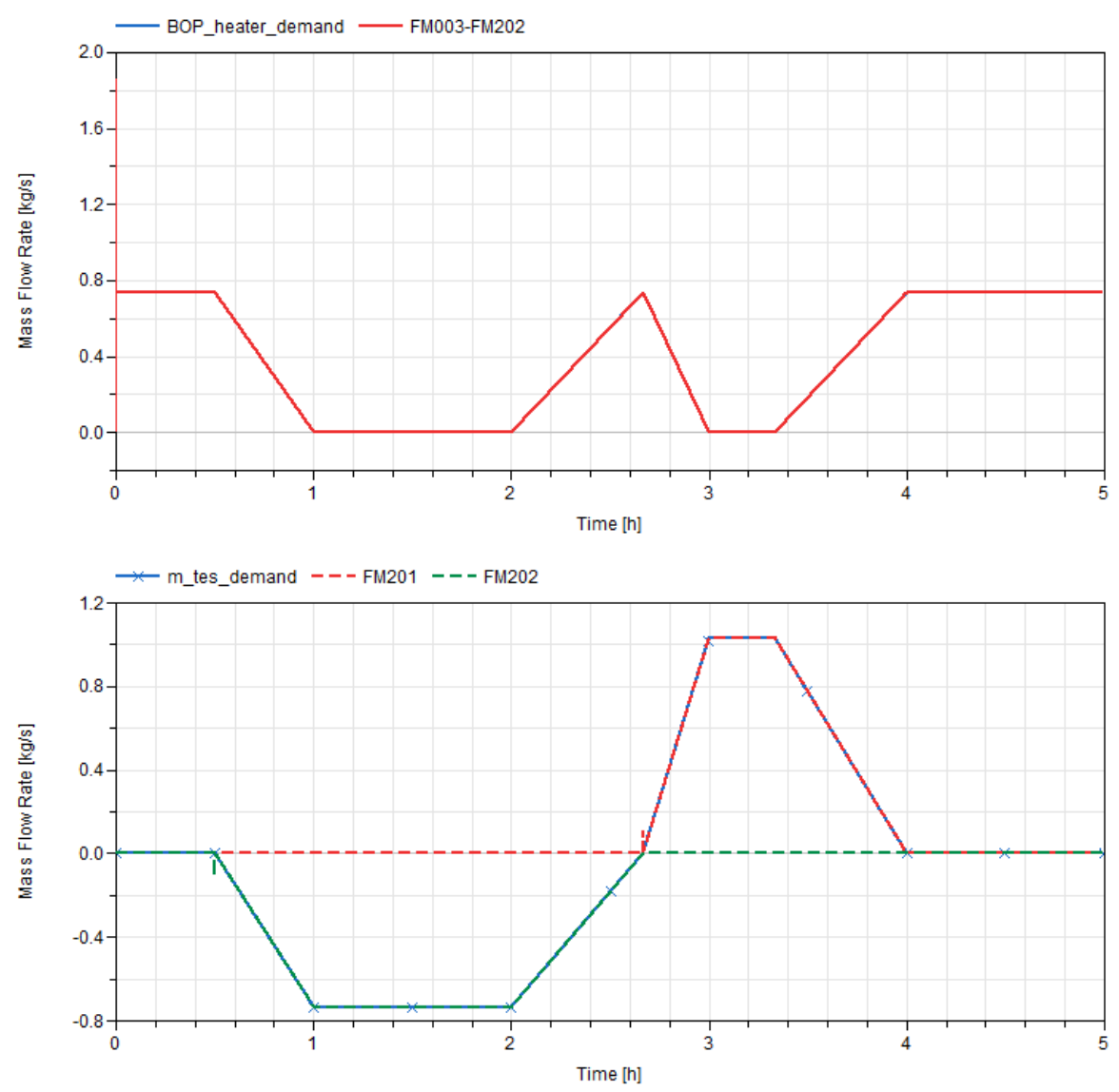

Figure 13. (Top) Balance of plant mass flow rate. (Bottom) Thermal-energy storage mass flow rates vs. sensor reading.

This simulation while not entirely representative of a typical demand curve for electricity markets elucidates the control actions built into TEDS. Additionally, it should be noted when looking at the thermocline that heat losses occur over the course of the simulation through the tank walls, and insulation at a rate of approximately $0.4^{\circ} \mathrm{C}$ per hour. Assuming a cyclical charging and discharge cycle, this heat loss would be made up in accordance with exit temperature and temperature control mechanisms in the system. However, if a prolonged period of stagnant flow is present in the system, exit temperatures from the thermal storage tank will present additional challenges to the system and, at a certain point, the fluid in the thermal storage unit will no longer be useful to the system. Therefore, long duration storage on the order of days or weeks is not ideal for TEDS unit operation.

\subsection{Summer Day Test}

The previous simulation case demonstrates the capability of the system to operate through all foreseeable operational modes. An advantage of TEDS is the ability to system components relative to regional grid buildout. To demonstrate this ability, TEDS was subjected to the load of a hot summer day [17] in an area with mixed commercial and residential electricity needs (Figure 14). The system is sized to represent a nuclear generator coupled to a thermal storage unit that has $12.5 \%$ peaking capacity for a constrained grid scenario. So, at peak demand, the thermal storage unit can be utilized as a peaking unit to meet that demand. The mean net demand can be met entirely with the nuclear generator, while during 
times of low net electricity demand ${ }^{1}$, excess capacity can be stored in the thermal storage tank. System parameters are identical to those utilized in Table 5.

Initially, the thermal storage tank is assumed to be $66 \%$ charged. The first hour of the simulation is used to stabilize the system from a numerical perspective, and charging-side temperatures are higher than $225^{\circ} \mathrm{C}$ because of initialization conditions on the tank walls. Hour 1 corresponds to midnight. Starting from time zero, demand is lower than the potential Chromalox heater output, and excess capacity is therefore sent to the thermocline tank for storage. This process continues for the next $51 / 2$ hours with a maximum charging rate of $20 \mathrm{~kW}$ occurring at hour 4 (or $3 \mathrm{a} . \mathrm{m}$.). Then, at the $61 / 2$-hour mark, or 5:30 a.m., as people begin to get up, the temperature begins to rise and air conditioning units turn on, total demand reaches the maximum output of the Chromalox heater, and charging ceases. From hour 6 to hour 22 (9:00 p.m.), demand is higher than heater output and discharge operation begins. During discharge operation, hot fluid in the thermocline tank is sent to the chiller to simulate the amount of heat required to boil steam and produce energy for the community. Throughout the discharge cycle, cold fluid is pumped into the bottom of the chiller and the hot fluid is pumped out.
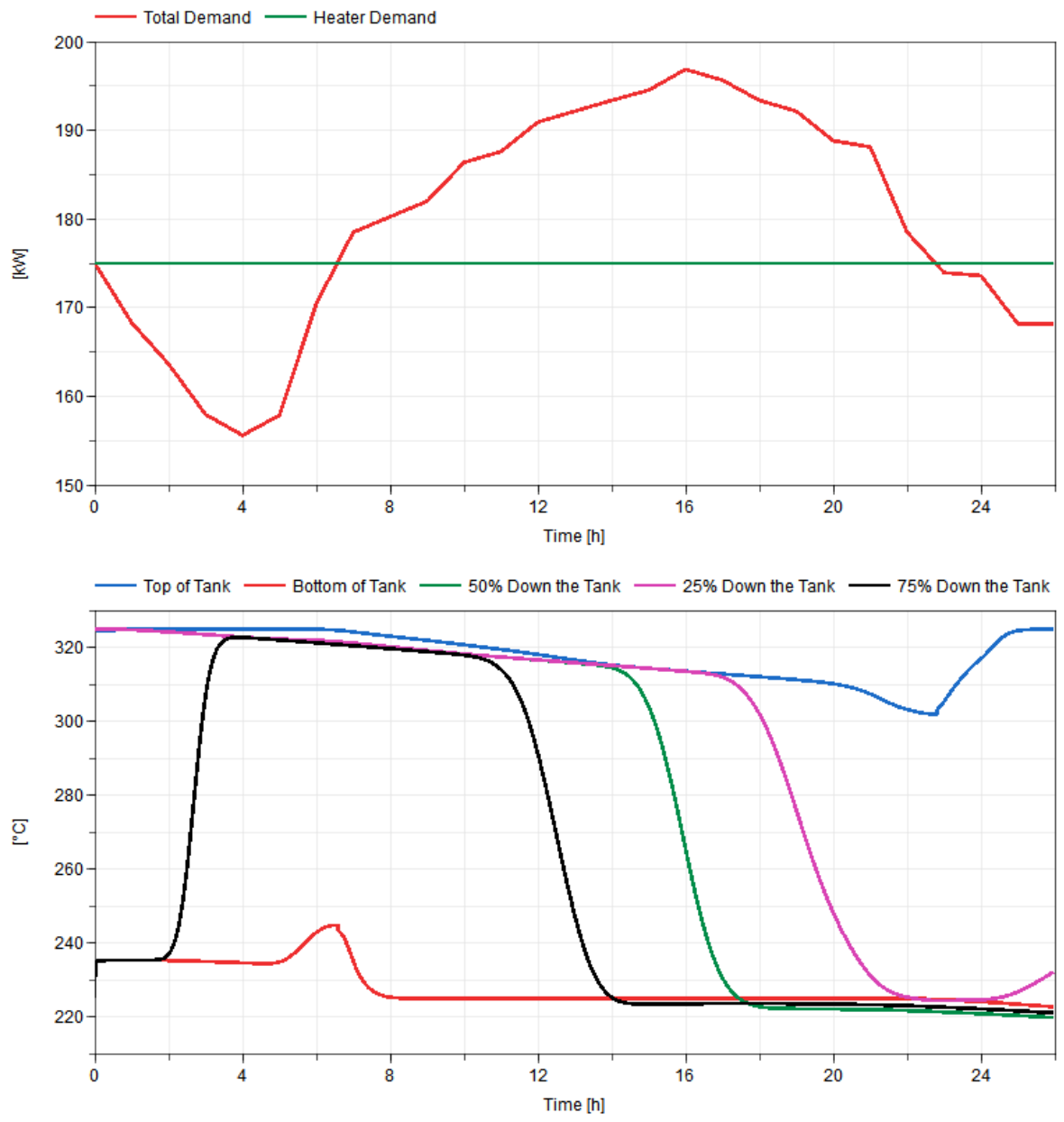

Figure 14. (Top) System demand on heater, thermocline, and total system. (Bottom) Thermocline fluid temperature at varying points within the tank.

\footnotetext{
${ }^{1}$ Net demand $=$ Total Demand - Renewable Energy
} 
Over the course of the simulation, heat loss to the ambient surroundings causes a dramatic decrease in temperature throughout the thermocline tank, as shown in Figure 14. This decrease in temperature is further exacerbated as flow from colder regions of the tank mixes with hotter regions during the charge and discharge cycles. These heat losses, while minor over an hour, become more pronounced as the heat is stored for long periods of time. Initial discharge outlet temperature is $\sim 325^{\circ} \mathrm{C}$, while at hour 21 the outlet temperature has been reduced from ambient heat losses and internal mixing in the tank to $\sim 310^{\circ} \mathrm{C}$. The degradation will lead to efficiency losses in the overall process and, at a certain point, the outlet temperature will fall below a "useful" temperature threshold. This phenomenon is important to incorporate into the system control strategy moving forward for IES that intend to utilize packed-bed thermocline systems.
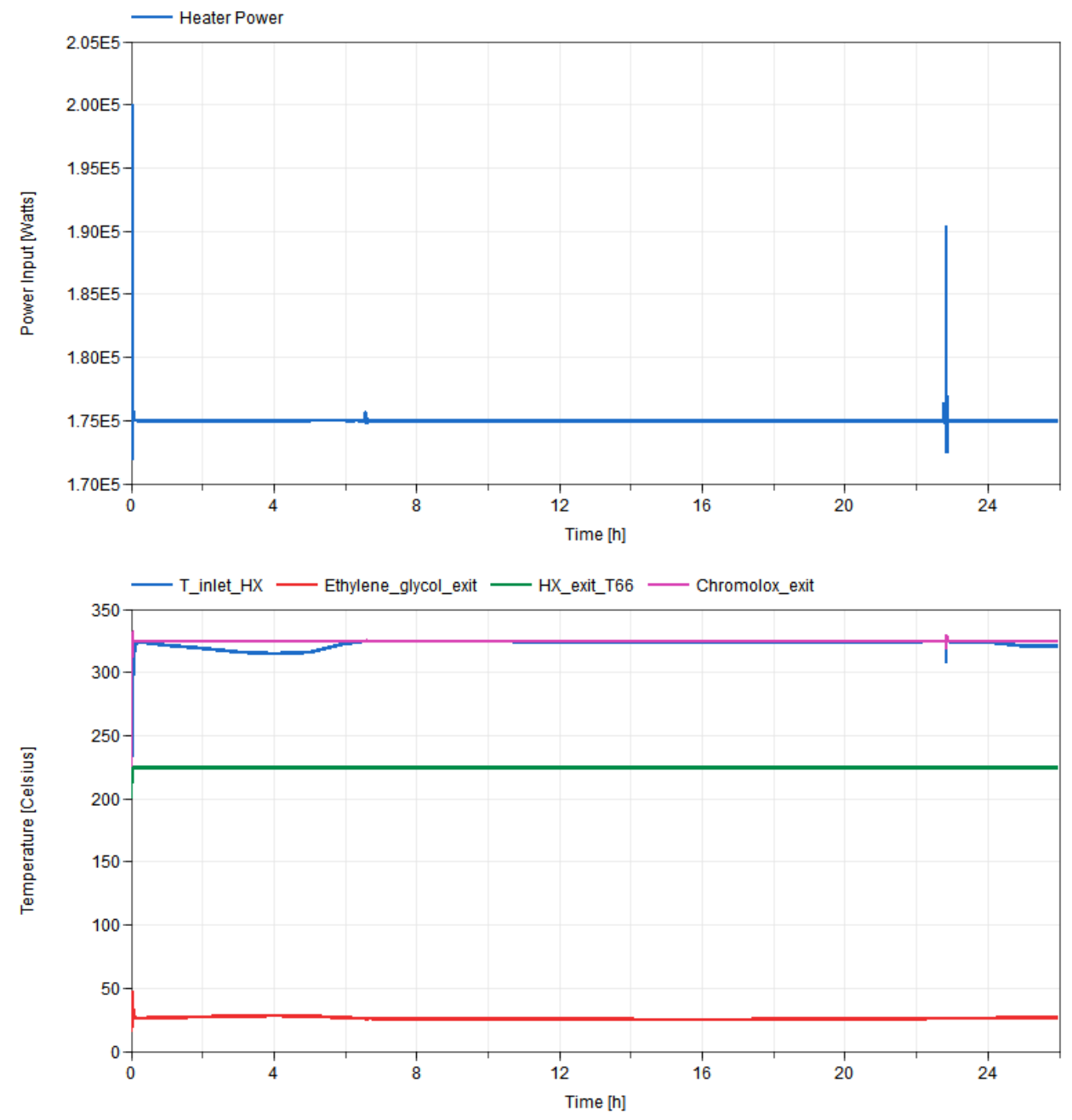

Figure 15. (Top) Chromalox heater input. (Bottom) Temperatures throughout the TEDS loop.

Heater power throughout the run is at $175 \mathrm{~kW}$ aside from slight fluctuations that occur as the system transitions from mode to mode, as shown in Figure 15. Chromalox heater exit temperature is maintained at $325^{\circ} \mathrm{C}$ throughout the simulation, ethylene glycol flow rate never decreases to a point where potential boiling occurs as there is always a higher inlet temperature to the heat exchanger than the setpoint exit temperature of $225^{\circ} \mathrm{C}$. 

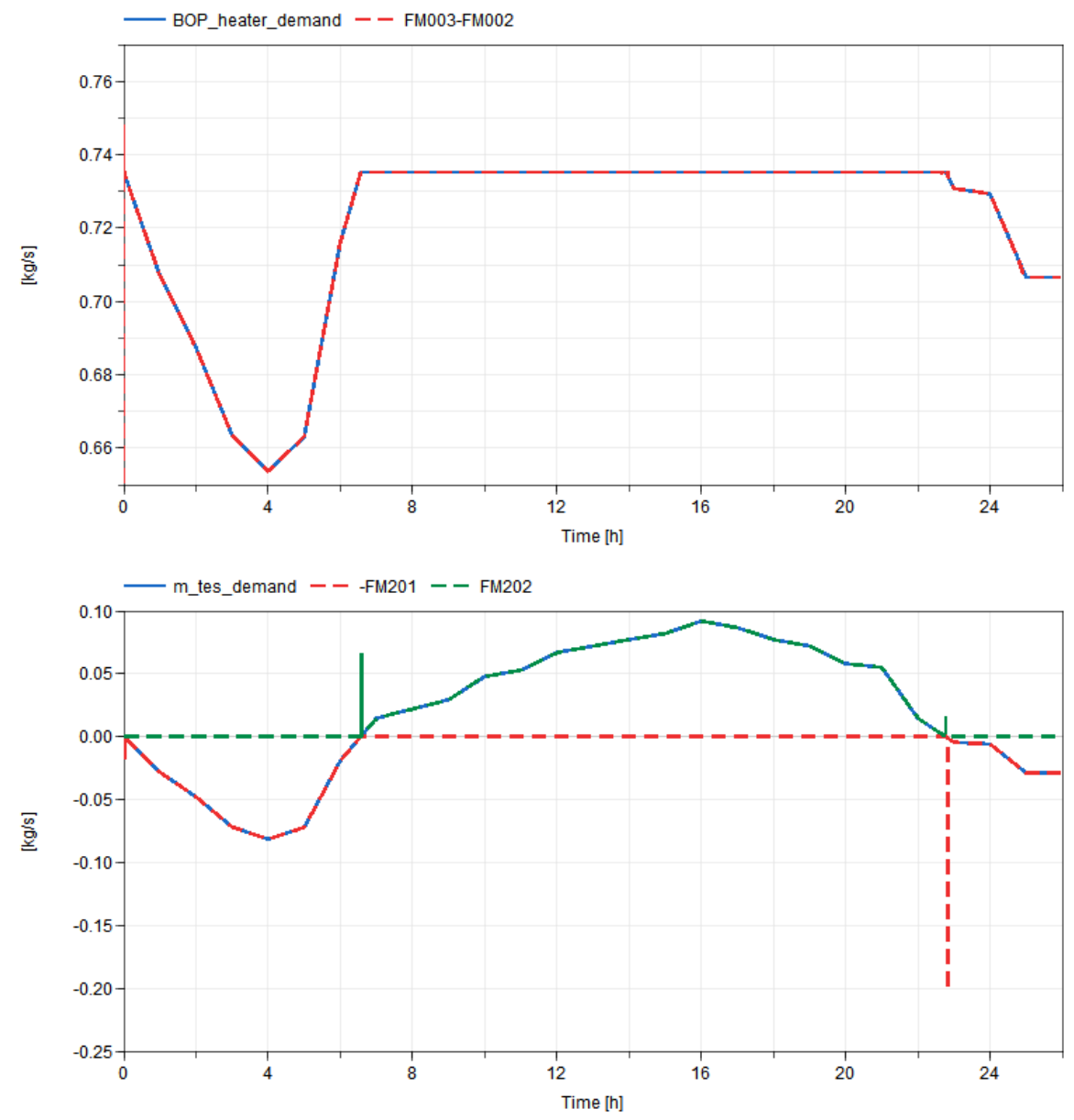

Figure 16. (Top) Balance of plant mass flow rate. (Bottom) Thermal-energy storage mass flow rates vs. sensor reading.

Throughout the run balance of plant, heater demand does not ever go to zero, which would initiate GBV-006 to close. Instead GBV-006 modulates throughout the run to meet heater demand based on a signal of mismatch between demand and the combination of flow meters FM-003 and FM-002.

Throughout the run, GBV-006 closely matches this demand without any major overshoot or undershoot in flow. Thermal storage demand however operates on smaller demand signals and with an interlocking valve on both the charge and discharge lines. Thermal storage demand is negative by convention if charging is desired and positive if discharge is desired. During charging, GBV-201 modulates in accordance with the desired demand and flowmeter FM-201 and is able to match charging demand with charging flowrate with little to no overshoot aside from hour 23 where massive overshoot occurs as the valve first begins to open. This is attributable to three things. First, there was a long period of zero demand on the valve and therefore there was a large windup of integral term error in the signal. Second, the charging and discharge lines operate on interlocks to ensure there is a never a moment where both lines are open simultaneously. Third, valve modulations when first opening have a much larger effect on mass flow fluctuations than when opening in the middle band of valve position. Similarly, during discharge GBV-202 modulates in accordance with the desired demand and flowmeter FM-202 and is able to match discharge demand with little to no overshoot aside from a little past hour 6 where massive overshoot occurs as the valve first begins to open. This overshoot is quickly subdued and GBV-202 can meet discharge demand. 


\section{CONCLUSIONS}

Model development has led to the creation of a dynamic systems-level model of the experimental TEDS facility in the Modelica language, capable of operating under all potential modes set forth by the design team. Development included the creation of property modules for therminol-66, Alumina, FOAMGLAS ${ }^{\circledR}$ ONE, and ethylene glycol (DowTherm SR-1) that have been incorporated in the TRANSFORM library at ORNL. Control algorithms have been developed to be consistent with exposed variables within the experimental facility to allow for the seamless integration of control algorithms proposed in this report. The model includes the primary components of the TEDS experimental unit, including: a 200kW Chromalox heater, a single-tank packed-bed thermal-energy storage system filled with 0.125 inch Alumina $\left(\mathrm{Al}_{2} \mathrm{O}_{3}\right)$, an ethylene-glycol-to-therminol-66 heat exchanger, system piping, five control valves, and all associated temperature, pressure, and mass flow sensors. The model does not include nitrogen-fill gas tanks or associated overfill tanks as these are not part of standard system control.

The model was used during the preconstruction phase of the experimental effort to inform experimental design (insulation requirements, bypass line placement, expected performance of components) and to test innovative control schemes prior to the initial operation. Through simulation it was determined that a 6-inch layer of FOAMGLAS ${ }^{\circledR}$ ONE insulation was required for the thermocline tanks to help minimize heat losses while still fitting within the physical footprint of the experiment. Additionally, it was determined that a bypass line on the therminol-66 side of the heat exchanger or a minimum ethylene glycol mass flow rate is required to ensure zero boiling of the ethylene glycol can occur in either mode- 4 or mode- 2 operation. This requirement is leading to the inclusion of a bypass line on the oil side of the oil-glycol heat exchanger that was not previously envisioned.

Two simulation sets were run. The first is a 5-hour test that operates as a shakedown test for the facility. This simulation puts the facility through all five potential operating modes and showcases the ability of valving, control sensors, and component controllers to meet the system demands. During shakedown testing, it was noted that a minimum mass flow rate on the ethylene glycol chiller of $0.05 \mathrm{~kg} / \mathrm{s}$ would be required to ensure bulk boiling of the glycol did not occur. This requirement likewise led to an $\sim 15 \mathrm{~kW}$ increase in heater power to ensure exit temperatures were maintained at $325^{\circ} \mathrm{C}$. In the future, a bypass line will be installed on the therminol-66 side of the heat exchanger to mitigate this issue.

The second case imposed a typical summer day demand on the system from a region with mixed commercial and residential electrical needs where the generator alone cannot meet peak demand, but instead requires the thermal storage unit to act as a peaking unit. Over the day, valving and sensors were able to meet demand as expected. However, there occurred a large amount of thermal degradation due to external heat loss. Over the course of the 15-hour discharge cycle, heat losses account for a heat loss of approximately $15^{\circ} \mathrm{C}$ in outlet temperature. Such heat losses would lead to a decrease in overall system efficiency and may lead to additional design changes for such designs in the future that may include a topping heater.

Through commencement of this work, a systems-level model of TEDS with associated control systems, sensors, piping diameters, and component capabilities has been created. This model has been utilized in the pre-experimental phase to inform system design, insulation thicknesses, bypass line placement, and potential control schemes to operate the system effectively and safely. Now that TEDS is beginning operation, this model will be refined, tuned, and used for validation and verification purposes of other models utilized in the M\&S framework for IES. 


\section{ACKNOWLEDGEMENTS}

This work was supported by the Integrated Energy Systems program at Idaho National Laboratory under DOE Operations contract number DE-AC07-05ID14517.

\section{REFERENCES}

1. C. Rabiti, A. S. Epiney, P. Talbot, J. S. Kim, S. Bragg-Sitton, A. Alfonsi, A. Yigitoglu, S. Greenwood, S. M. Cetiner, F. Ganda, G. Maronati, "Status Report on Modeling and Simulation Capabilities for Nuclear-Renewable Hybrid Energy Systems," Idaho National Laboratory, September 2017, INL/EXT-17-43441.

2. Jong S. Kim, Michael McKellar, Shannon Bragg-Sitton, Richard Boardman. "Status Report on the Component Models Developed in the Modelica Framework: High-Temperature Steam Electrolysis \& Gas Turbine Power Plant.” Oct 2016. INL/EXT-16-40305. Revision 0.

3. Jong S. Kim, Konor L. Frick. "Status Report on the Component Models Developed in the Modelica Framework: Reverse Osmosis Desalination Plant \& Thermal Energy Storage.” May 2018. INL/EXT18-45505 Revision 0.

4. Konor L. Frick, "Status Report on the NuScale Module Development in the Modelica Framework." Idaho National Laboratory. August 2019. INL/EXT-19-55520.

5. Dassault Systems. DYMOLA Systems Engineering [Internet]. [updated 2020 May 28; cited 2018 May 16]. Available: https://www.3ds.com/products services/catia/products/dymola/.

6. Modelica Association. Modelica Standard Library [Internet]. [updated 2018 May 22; cited 2018 May 16]. Available: https://github.com/modelica/Modelica.

7. M.S. Greenwood: TRANSFORM - TRANsient Simulation Framework of Reconfigurable Models. Computer Software. https://github.com/ORNL-Modelica/TRANSFORM-Library. 07 Nov. 2017. Web. Oak Ridge National Laboratory. doi:10.11578/dc.20171109.1. Available: https://github.com/ORNL-Modelica/TRANSFORM-Library.

8. K. Frick, A. Duenas, P. Sabharwall, J. Yoo, S. Yoon, C. Stoots, J. O’Brien, T. O’Brien. "Thermal Energy Delivery System Operational Characteristics and Control Strategies." INL/CON-18-51322Rev000

9. C. Stoots, A. Duenas, P. Sabharwall, J. O’Brien, J. Yoo, S. Bragg-Sitton. "Thermal Energy Delivery System Design Basis Report.” Idaho National Laboratory. September 2018. INL/EXT-18-51351 Revision 00.

10. J. Lew, P. Li, C. Chan, W. Karaki, J. Stephens. "Analysis of Heat Storage and Delivery of a Thermocline Tank Having Solid Filler Material.” Journal of Solar Energy Engineering. Vol. 133. May 2011.

11. T. Esence et al. "A review on experience feedback and numerical modeling of packed-bed thermal energy storage systems." Solar Energy. Vol. 153. Pages 628-654. 2017.

12. "Therminol 66: High Performance Highly Stable Heat Transfer Fluid," Applied Chemistry, Creative Solutions, Solutia, Inc., St. Louis, Missouri; https://www.therminol.com.

13. MEGlobal. Monoethylene Glycol. https://www.meglobal.biz/wpcontent/uploads/2019/01/Monoethylene-Glycol-MEG-Technical-Product-Brochure-PDF.pdf

14. "Engineering and Operating Guide for DOWTHERM SR-1 and DOWTHERM 4000 Inhibited Ethylene Glycol-based Heat Transfer Fluids.” DOW Chemical. 
15. Ronald Munro. "Evaluated Material Properties for a Sintered $\alpha$-Alumina." Journal of American Ceramics. Volume 80. Pgs. 1919-1928. 1997.

16. FOAMGLAS ONE. Pittsburgh Corning. www.foamglas.com.

17. Konor Frick, J. Michael Doster, Shannon Bragg-Sitton (2018): "Design and Operation of a Sensible Heat Peaking Unit for Small Modular Reactors.” Nuclear Technology, 205:3, 415-441, DOI:10.1080/00295450.2018.1491181. 